Published in final edited form as:

J Clin Child Adolesc Psychol. 2017 ; 46(3): 303-330. doi:10.1080/15374416.2016.1220309.

\title{
Evidence Base Update for Psychosocial Treatments for Children and Adolescents Exposed to Traumatic Events
}

\author{
Shannon Dorsey, \\ Department of Psychology, University of Washington
}

Katie A. McLaughlin,

Department of Psychology, University of Washington

\author{
Suzanne E. U. Kerns*, \\ Department of Psychiatry and Behavioral Science, University of Washington
}

Julie P. Harrison,

Department of Psychology, University of Washington

Hilary K. Lambert,

Department of Psychology, University of Washington

\section{Ernestine C. Briggs,}

Department of Psychiatry and Behavioral Sciences, Duke University School of Medicine

Julia Revillion Cox, and

Department of Psychology, Virginia Commonwealth University

\section{Lisa Amaya-Jackson}

Department of Psychiatry \& Behavioral Sciences, Duke University School of Medicine

\section{Abstract}

Child and adolescent trauma exposure is prevalent, with trauma exposure-related symptoms, including posttraumatic stress, depressive, and anxiety symptoms often causing substantial impairment. This article updates the evidence base on psychosocial treatments for child and adolescent trauma exposure completed for this journal by Silverman et al. (2008). For this review, we focus on 37 studies conducted during the seven years since the last review. Treatments are grouped by overall treatment family (e.g., cognitive behavioral therapy), treatment modality (e.g., individual vs. group), and treatment participants (e.g., child only vs. child and parent). All studies were evaluated for methodological rigor according to Journal of Clinical Child \& Adolescent Psychology evidence-based treatment evaluation criteria (Southam-Gerow \& Prinstein, 2014), with cumulative designations for level of support for each treatment family. Individual CBT with parent involvement, individual CBT, and group CBT were deemed well-established; group CBT with parent involvement and eye movement desensitization and reprocessing (EMDR) were deemed probably efficacious, individual integrated therapy for complex trauma and group mind-

Correspondence should be addressed to Shannon Dorsey, Department of Psychology, University of Washington, Guthrie Hall, Box 351525, Seattle, WA 98195. Tele: 206.543.2640. dorsey2@uw.edu.

* Current affiliation: Graduate School of Social Work, University of Denver. 
body skills were deemed possibly efficacious; individual client-centered play therapy, individual mind-body skills, and individual psychoanalysis were deemed experimental; and group creative expressive + CBT was deemed questionable efficacy. Advances in the evidence base, with comparisons to the state of the science at the time of the Silverman et al. (2008) review, are discussed. Finally, we present dissemination and implementation challenges and areas for future research.

Trauma exposure is pervasive among children and adolescents. Epidemiological data indicate that nearly two thirds of children in the United States will experience a traumatic event before their 18th birthday (Copeland, Keeler, Angold, \& Costello, 2007; McLaughlin et al., 2013). Although comparable epidemiological studies are not available internationally, substantial rates of trauma exposure during childhood and adolescence have also been reported in other high-income (e.g., Trocmé \& Wolfe, 2001) and low-income (e.g., Benjet et al., 2009) countries. In the United States, adolescence in particular may be a period of high risk for exposure to virtually all types of traumatic events, including interpersonal violence, accidents, injuries, unexpected loss of a loved one, and traumatic events that happen to friends or family (Breslau et al., 1998; Finkelhor, Ormrod, \& Turner, 2009); U. S. Census Bureau, 2012).

Although not all children exposed to trauma have symptoms of distress, an array of shortand long-term mental health consequences have been identified in the literature. Symptoms of posttraumatic stress disorder (PTSD) are perhaps one of the most researched responses that may develop following exposure to a traumatic event and are the symptom category most often used for study inclusion criteria. Population-based studies suggest that approximately $7 \%$ of girls and 3\%-4\% of boys develop PTSD during childhood or adolescence (Kilpatrick et al., 2003; McLaughlin et al., 2013). Many more exhibit subclinical levels or symptoms of PTSD (Copeland et al., 2007). PTSD is associated with numerous adverse developmental consequences for children and adolescents in cognitive, academic, social, emotional, and other functional domains (De Bellis, Hooper, Woolley, \& Shenk, 2010; Leskin \& White, 2007; Moradi, Taghavi, Neshat-Doost, Yule, \& Dalgleish, 2000; Trickett, Noll, \& Putnam, 2011) and with an elevated risk for the subsequent onset of other mental disorders (e.g., depression, anxiety; Giaconia et al., 1995). Other mental health sequelae of trauma-exposed youth include behavioral problems, depressive symptoms, and anxiety $(19.2 \%, 12.1 \%$, and 9.8\%, respectively, in the Great Smoky Mountains Study; Copeland et al., 2007). Potentially most important, among children with any exposure, more than one fifth (21.9\%) report significant impairment, with higher rates of impairment for two or more exposures (49.6\%; Copeland et al., 2007). Timely delivery of evidence-based treatment (EBT) to children and adolescents with trauma-related mental health sequelae is critical to prevent negative consequences of trauma exposure.

Given the pervasive nature of trauma exposure and potential mental health consequences, the field has attempted to consolidate knowledge about treatment approaches. The primary purpose of this article is to update the review published in this journal in 2008 (Silverman et al., 2008) on psychosocial EBTs for children and adolescents exposed to trauma. In their review, the authors evaluated 21 randomized controlled trials (RCTs). Two treatments, both 
of which were cognitive behavioral therapies (CBTs), met either the well-established or probably efficacious criteria for improving child and adolescent outcomes (e.g., Posttraumatic Stress Symptoms [PTSS], depressive symptoms, anxiety symptoms, and externalizing behavior problems). Trauma-focused cognitive behavioral therapy (TF-CBT; Cohen, Deblinger, \& Mannarino, 2006) was rated as well-established and school-based group cognitive-behavioral therapy (Kataoka et al., 2003) was rated as probably efficacious. All other included treatments were classified as possibly efficacious or experimental. Across all 21 RCTs, meta-analytic results indicated that effect sizes were medium for PTSS (Cohen's $d=0.43$ ), followed by small effects for depression and externalizing behavior problems ( 0.24 and 0.22 , respectively) and minimal effects for anxiety $(0.09)$. Three potential moderators, each aggregated at two levels given the small number of studies, were examined: type of treatment, trauma type, and parental involvement. Type of treatment moderated effectiveness, with CBT (vs. non-CBT) having more than 2 times the effect size of non-CBT for PTSS (0.50 vs. 0.19), depression (0.29 vs. 0.08 ), and externalizing behavior problems ( 0.24 vs. 0.02 ). Type of trauma — child sexual abuse versus other typesmoderated outcomes, with larger effect sizes when sexual abuse was the focus for internalizing outcomes (PTSS and depression, $d=0.30-0.46$ ) and smaller effect sizes for externalizing behavior problems, compared to other trauma types ( 0.19 vs. 0.28 ; inclusive of family violence and physical abuse). Parental involvement (child and parent participate vs. child only; collapsed across treatment types) had more mixed results, depending on whether treatments were being compared to other active treatments or no treatment controls.

However, taken together, there was little difference for PTSS (0.42 vs. 0.44$)$ and slightly less effectiveness for depression ( 0.19 vs. 0.25$)$ when parents were involved. Anxiety differed substantially, favoring parent involvement ( 0.16 vs. -0.01 ). Surprisingly, results supported child-only treatment for improving externalizing behavior problems (0.14 vs. 0.34$)$. When treatments with active control groups were examined separately, effect sizes were similar or slightly smaller.

Since the Silverman et al. (2008) review, there have been a substantial number of studies on treatments targeting mental health symptoms related to trauma exposure, necessitating an update to the evidence base. Also during this same period, our search identified 17 other reviews of treatment for child trauma exposure sequelae (see Table 1), each taking a slightly different approach toward reviewing in terms of inclusion criteria, index trauma (e.g., sexual abuse, war exposure), setting or modality (e.g., group therapy, interventions in schools), or treatment focus (e.g., CBT-only interventions, single name-brand, treatment-focused review [e.g., TF-CBT]).

These included qualitative, systematic, and meta-analytic reviews, with conclusions from most reviews providing support for CBT (see Table 1 for more details).

\section{Does the Field Need Another Review of Trauma Treatment Interventions? Specific Contribution of This Evidence Base Update}

In the current evidence base update article, we advance the science by examining the evidence for treatment of symptoms related to child trauma exposure since the Silverman et 
al. (2008) review. Like Silverman et al., we include all types of trauma exposure, from sexual abuse and other forms of child maltreatment to natural disaster and war/systematic violence exposure. We include a broad range of treatment approaches (e.g., CBT, eclectic, play therapy), as well as individual and group delivery modalities. We chose not to limit our review to RCTs to better capture research focused on ethnically and culturally diverse populations and conducted in varying settings and contexts. Another unique aspect of this review is a focus on intervention setting and on who delivered the intervention. Increasingly in trauma treatment, the evidence base includes studies conducted in usual care settings (i.e., schools, public mental health clinics vs. university or hospital-affiliated clinics), with delivery of interventions by providers already employed in these settings (vs. highly trained, doctoral-level mental health professionals).

This review focuses only on studies that specifically assessed child and adolescent participants for both trauma exposure (experienced or witnessed) and mental health symptom impact (e.g., elevation on some indicator of mental health problems). This method excludes a large number of studies that meet only one of these criteria (e.g., trauma exposure but not mental health symptoms) or assume child exposure due to residence in an area with high rates of violence. These inclusion criteria differ from those in the Silverman et al. (2008) review, in which symptom inclusion was not required. In addition, only RCTs were examined in Silverman et al., and the focus was on "name-brand" treatments and not classes of treatment (e.g., individual CBT). Limiting included studies to those that assess for trauma impact - and not only exposure-is in line with recommendations from Foa and Meadows (1997) and other reviews in this evidence base update series. Foa and Meadows (1997) argued that including non- or mildly symptomatic participants can be problematic, as treatment effects can be either minimized (as it may be difficult to detect improvement) or inflated (given that participants with mild symptoms at baseline may also have only mild symptoms at follow-up).

One of the most beneficial contributions of this review is organization by treatment classes or treatment families (Southam-Gerow \& Prinstein, 2014; similar to review conducted by Wethington et al., 2008). Treatments have a number of common or overlapping elements, and understanding treatment effectiveness while taking into account this overlap is important for knowledge management. Dissemination and implementation researchers increasingly have been moving in the direction of identifying and testing approaches that distill these common elements (e.g., Weisz et al., 2012) to simplify recommendations for the field and for training providers.

Our goal, given the combination of recent growth in studies focused on treating symptoms related to trauma exposure and Southam-Gerow and Prinstein's (2014) expanded evidence review criteria (see Table 2), is to provide a broader, more inclusive review of the evidence for overarching treatment classes, with attention to relevant aspects for dissemination and implementation (e.g., testing under more usual care conditions) and decision-making around next steps for the research. Including attention to these aspects allows for a better understanding of the potential impact of these treatments if they attained greater population reach. Although we included a broad range of studies (i.e., not only RCTs), methodological strengths and weaknesses for each study are taken into account in evidence ratings. This 
allowed for comprehensiveness in study inclusion as well as the ability to weigh study rigor when assigning level of evidence. Results of our review are organized by level of evidence, starting with treatments that attained the highest level of evidence.

\section{METHOD}

\section{Search Parameters and First-Round Inclusion Criteria}

A systematic, comprehensive literature search was conducted in PsycINFO and PubMed with the aim of identifying all peer-reviewed articles related to the treatment of traumarelated sequelae in children and adolescents. Several steps were taken in the search process to maximize the number of relevant articles returned while minimizing the number of irrelevant articles (see Figure 1). First, the authors generated an inclusive list of search terms related to two categories: trauma exposure and treatment. Second, the authors refined the items on this list for PsycINFO and PubMed queries. In PsycINFO, each author-generated term was entered into the Thesaurus Authority File search tool—which contains terms from the American Psychological Association's Thesaurus of Psychological Index-and replaced with all relevant returned search terms. For example, the author-generated search term "trauma" was replaced with "emotional trauma," "posttraumatic growth," "debriefing (psychological)," and "eye movement desensitization therapy." Similarly, in the PubMed database, the Medical Subject Headings thesaurus search tool—which contains the controlled search term vocabulary for the National Library of Medicine-was used to refine each author-generated search term. For example, the term "treatment" was replaced with "treatment outcome," a more specific search term used within the PubMed database. Third, search results were limited by publication date (January 2007-May 2014), species (humans), age ( $0-18$ years), and publication type (peer-reviewed journal). Fourth, to maximize the number of relevant articles returned, all terms were simultaneously entered into the search to include all cross-category ([1] trauma exposure, [2] treatment) combinations. To ensure all returned articles pertained to both trauma exposure and treatment, the AND operator was used to separate the two categories and, within each category, search terms were separated using the OR operator.

All studies included in this evidence base update passed through two rounds of review (see Figure 1). Articles were selected for the first round if they satisfied the initial inclusion criteria: (a) participants with potential trauma exposure (following the Diagnostic and Statistical Manual of Mental Disorders [4th ed.; American Psychiatric Association, 1994] definition) and (b) measures of psychological outcomes. Relevant information was gathered from article titles, abstracts, and method sections; decisions erred on the side of overinclusion. Although research articles were the focus of the search, relevant review articles returned by the search were also examined for additional references. This search and review method yielded 188 articles, which were included in the second-round review.

\section{Second-Round Inclusion Criteria to Identify the Study Pool}

In the second-round review, the goal was to identify the final set of studies. Five authors made the final decision for article inclusion using a stricter set of inclusion/exclusion criteria, detailed in Figure 1 (e.g., sample was 18 or younger, study focused on treatment of 
trauma-exposure sequelae, etc.). Studies examining pharmacological interventions were not included unless they were paired with a psychosocial intervention. During this review round, authors read the full-text articles. Out of the 188 articles from the first round, 151 were excluded in the second round, leaving 37 articles included in the review.

Categorization by Treatment Family-Included studies were coded by modality (group vs. individual delivery), treatment participants (child only vs. child and parent), and treatment type. Studies with fewer than 50 participants were categorized as "small." Treatments were categorized as including "parent involvement" if one or more parents were involved nearly $50 \%$ or more or the time (via parent-only or combined child-parent sessions, and/or observation of sessions). Treatments that included minimal or optional parent involvement were coded as "child." Categorization of treatment type was typically straightforward in that treatments' names or descriptions included their primary theoretical basis (e.g., CBT, psychodynamic, attachment). However, in some instances, the treatment included more than one theoretical basis or was eclectic. In these situations, treatments were categorized by primary theoretical basis with notation of other theoretical influences.

\section{RESULTS}

Our review is based on 37 studies that were published since 2007 that met the review criteria (see Table 3). Six (16.2\%) of these focused on sexual abuse, suggesting that studies of treatment for trauma-related symptoms have broadened in focus since the last review beyond predominantly sexually abused children and adolescents. Twenty studies included children with varying trauma exposure (54.1\%), six with exposure to terrorism/war (16.2\%), three with childhood physical abuse and/or family violence (8.1\%), two with exposure to other traumatic events (5.4\%), one study with exposure to natural disaster/death, and one study with exposure to other (i.e., factory explosion). Of those that reported ethnicity/cultural group, $13(35.1 \%)$ were conducted with diverse cultural or ethnic populations, and 17 (45.9\%) were conducted outside the United States. Schools were the most common treatment setting $(10 ; 27 \%)$, followed by community clinics $(7 ; 19 \%)$ and university or hospital-based clinics $(6 ; 16 \%)$. Seven studies did not report treatment setting. Although not always reported clearly in the studies, providers were mostly master's level and trainees, which is representative of individuals who deliver the vast majority of mental health treatment. Five studies (13.5\%) used non-mental-health professionals. Similar to the Silverman et al. (2008) review, outcome variables most commonly assessed were PTSD and PTSS ( 35 of 37 studies; 94.6\%), with depression being the second most commonly assessed outcome $(19 ; 51.4 \%)$. In contrast to the prior review, a greater percentage of studies (17; 45.9\%) assessed externalizing behavior problems. Other child-level outcomes assessed by two or more studies included functioning $(13 ; 35.1 \%)$, anxiety $(10 ; 27 \%)$, general mood symptoms $(5 ; 13.5 \%)$, sexual behavior $(3 ; 8.1 \%)$, strength/resiliency $(3 ; 8 \%)$, and grief $(2$; $5 \%)$.

Our narrative review provides a summary of research findings for each treatment family. Results are organized by level of evidence for each treatment family (see Table 4), with treatments in Levels 1 and 2 described. 


\section{Level 1: Well-Established}

Individual CBT with Parent Involvement-The Silverman et al. (2008) review included six studies testing individual CBT with parent involvement, four of which tested TF-CBT specifically (Cohen et al., 2006). Five of the six focused on sexual abuse as the index traumatic event. TF-CBT remains the most commonly studied version of child- and parent-focused CBT. TF-CBT includes approximately 10-12 parallel, mostly separate child and parent sessions, with parents receiving the same elements as their children. Some treatment sessions include the child and parent together (i.e., conjoint sessions). Treatment elements include psychoeducation about trauma exposure and PTSS; coping skills (e.g., affect identification/modulation, relaxation, cognitive coping); imaginal exposure (i.e., explicitly recalling details, thoughts, and feelings about traumatic experiences; often through drawings, writing, or other creative mechanisms); in vivo exposure (i.e., through confronting innocuous trauma reminders); cognitive restructuring of maladaptive, trauma-related cognitions; and safety skills training. Parents are also taught parenting skills (e.g., praise, contingency management). Other individual CBT approaches with parent involvement, at least to date, include relatively similar treatment elements with some variation in how parents were involved (e.g., parallel sessions, conjoint sessions, observation of child sessions) and in whether elements were added (e.g., harm reduction for adolescents with substance use) or removed (e.g., cognitive processing for preschool children) based on youth age and comorbidity.

Since the original review, there have been 11 studies that met review criteria, including eight additional RCTs and three open trials (Danielson et al., 2010; Misurell, Springer, Acosta, Liotta, \& Kranzler, 2014; Murray et al., 2013). The research is still dominated by studies of TF-CBT (six of 11 studies), although three studies tested substantially adapted versions of TF-CBT and three studies tested other individual CBT with parent involvement approaches. Collectively, these 11 studies provide additional empirical support for TF-CBT specifically, and more support for the overall treatment family given increased research attention to alternative approaches. In the five RCTs testing CBT compared to non-CBT comparison conditions, for PTSS, individual CBT with parent involvement outperformed the waitlist control (WLC; Scheeringa, Weems, Cohen, Amaya-Jackson, \& Guthrie, 2011) and outperformed (Cohen, Mannarino, \& Iyengar, 2011; Danielson et al., 2012, by parent-report; Jensen et al., 2014) or was equivalent to (Danielson et al., 2012, by child-report) usual care or other active treatment (De Roos et al., 2011). Superior outcomes also were obtained for depression and anxiety in most studies (see De Roos et al., 2011, for an exception). Of note, a primary strength of research on approaches in this treatment family - at the time of the Silverman et al. (2008) review and in this update- has been the methodological rigor and sample size of the studies (although, see Macdonald et al., 2012, for concerns about bias).

Beginning with five of the six TF-CBT studies, two were effectiveness trials (Cohen et al., 2011; Jensen et al., 2014), increasing confidence in the generalizability of findings from TFCBT efficacy trials. One small RCT found almost no benefit from supplementing TF-CBT with sertraline (Cohen, Mannarino, Perel, \& Staron, 2007). An open trial in Zambia demonstrated reduced PTSS when TF-CBT was delivered by lay counselors with little to no formal mental health training or experience (Murray et al., 2013). These studies advance the 
evidence base by demonstrating effectiveness of TF-CBT beyond the index traumatic event of sexual abuse. The Cohen et al. (2011) RCT focused on youth exposed to intimate partner violence; Jensen et al. (2014) and Murray et al. (2013) focused on multiply traumatized youth. The sixth TF-CBT-focused RCT (Deblinger, Mannarino, Cohen, Runyon, \& Steer, 2011) was a dismantling study; it is discussed subsequently along with another dismantling RCT.

Two studies extend findings in the Silverman et al. (2008) review by testing individual CBT with parent involvement at the ends of the age continuum, where clinicians may have concerns about applicability and effectiveness (e.g., very young children; adolescents who have other problems that can complicate treatment). Scheeringa et al. (2011) tested an adaptation of TF-CBT with 3- to 6-year-old children. Only two of the TF-CBT studies in the Silverman et al. (2008) review included children younger than 5 years (i.e., Cohen \& Mannarino, 1996, 1997). Uniquely, in the Scheeringa et al. (2011) study, parents observed all individual child sessions in which they did not participate (via television). One small RCT (Danielson et al., 2012) and an open trial (Danielson et al., 2010) tested Risk Reduction through Family Therapy (RRFT) a treatment approach that integrates TF-CBT, Multisystemic Therapy principles, and other evidence-based interventions to address comorbid PTSD and substance use problems in addition to risky sexual behavior. In this small RCT, participants who received RRFT had lower levels of substance use, but there were no differences in sexual behavior.

Two RCTs conducted since the Silverman et al. (2008) review inform an important question -whether "explicit" exposure, either through imaginal (via the client recounting their traumatic experience/s; Deblinger et al., 2011) or both imaginal and in vivo (exposure to innocuous trauma triggers) (Nixon, Sterk, \& Pearce, 2012), is required. We use the term "explicit exposure" because in both studies, even in the conditions without explicit imaginal (Deblinger et al., 2011; defined as "trauma narration") and/or in vivo (Nixon et al., 2012) exposure, the authors acknowledge that participants still received some trauma exposure through other elements (e.g., psychoeducation about traumatic events, cognitive processing of trauma-related thoughts). Therefore, the dismantling studies were testing inclusion of "explicit" or overt exposure elements in which sessions focused specifically on talking about traumatic experiences and/or facing up to trauma triggers either in session or between sessions. Both dismantling studies found that the conditions were equally effective for PTSS at the end of treatment but that conditions with exposure were more effective for general anxiety (i.e., non-PTSS). In the Deblinger et al. (2011) study (which included 8- and 16session versions; see Table 3), children who received explicit exposure also had lower levels of fear associated with thinking about or talking about their abuse. A follow-up study to Deblinger et al. (2011) documented maintained gains or improvement (i.e., child anxiety) for all conditions at 6 and 12 months, with differences between conditions no longer detectable (Mannarino, Cohen, Deblinger, Runyon, \& Steer, 2012).

Additional advancements include evidence for brief versions (eight or fewer sessions) of individual CBT with parent involvement and expanded evidence with culturally diverse youth. Four studies (two of which were the Deblinger et al., 2011, and Nixon et al., 2012, dismantling studies) provide some evidence of effectiveness for brief treatment. Eight- 
session versions of TF-CBT were essentially equivalent to similar 16-session versions (Deblinger et al., 2011) or more effective than an eight-session non-CBT approach (Cohen et al., 2011). The third relatively small RCT $(N=52)$ found that a four-session version of CBT was equivalent to a four-session EMDR intervention (De Roos et al., 2011). Some advancements have been made in testing individual CBT with parent involvement with culturally diverse children and adolescents, increasing confidence in effectiveness for diverse youth in the United States (i.e., African American youth; Danielson et al., 2010, 2012), highincome countries outside the US (i.e., Norway, the Netherlands; Jensen et al., 2014; De Roos et al., 2011; respectively), and in low-income countries (i.e., Zambia; Murray et al., 2013).

The weaknesses of the research on individual CBT with parental involvement is that nonTF-CBT approaches have received less research attention. To date, some of the alternate versions that are innovative (e.g., RRFT) have only been tested in small (Danielson et al., 2010; Danielson et al., 2012) or relatively small studies (e.g., Scheeringa et al., 2011). Few studies included follow-up data; those that did mostly included shorter follow-up windows (e.g., 3-6 months; see Mannarino et al., 2012, for an exception).

Individual CBT-Individual CBT is an increasingly common approach to treating symptoms of child trauma exposure. This treatment family includes child-focused CBT approaches similar to TF-CBT (e.g., multicomponent interventions that include psychoeducation, coping skills, imaginal and in vivo exposure, cognitive processing, etc.). It also includes approaches predominantly focused on imaginal and in vivo exposure, with some psychoeducation and more minimal coping skills training. Treatment duration is typically between 12 and 14 sessions, although some recent studies have tested brief versions (three to eight sessions).

At the time of the Silverman et al. (2008) review, only two studies tested TF-CBT versions of individual CBT (i.e., Deblinger, Lippmann, \& Steer, 1996; King et al., 2000). Individual CBT was mostly equivalent to a condition with parent involvement and superior to treatment as usual (TAU), WLC, and a parent-only CBT condition; however, in Deblinger et al. (1996), the parent-involved conditions were superior for externalizing problems and depressive symptoms. Since the 2008 review, this treatment family has benefitted from substantial new research, with eight studies of individual CBT. These eight studies include six RCTs-four of which were small—and two open trials (Aderka, Appelbaum-Namdar, Shafran, \& Gilboa-Schechtman, 2011; Van Der Oord, Lucassen, Van Emmerik, \& Emmelkamp, 2010). Four of the six RCTs tested adapted versions of interventions originally developed for adults: Prolonged Exposure for Adolescents (PE-A; Foa, McLean, Capaldi, \& Rosenfield, 2013; Gilboa-Schechtman et al., 2010) and a child version of Narrative Exposure Therapy (kidNET; Catani et al., 2009; Ruf et al., 2010); two tested other individual CBT approaches (Salloum \& Overstreet, 2008; Shirk, DePrince, Crisostomo, \& Labus, 2014).

Collectively, these eight studies provide more evidence—although measured-for the clinical benefits of individual CBT. All studies included children age seven and older (none focused on very young children). Findings from three of the six RCTs demonstrated effectiveness for PTSS, PTSD diagnosis, depression, and functioning (see Table 3 for 
findings by study), with comparison conditions that were active treatments (Foa et al., 2013; Gilboa-Schechtman et al., 2010) or WLC (Ruf et al., 2010). The comparison group for the fourth RCT in this treatment family was group CBT (Salloum \& Overstreet, 2008), with equivalent findings for individual and group CBT. In two of the six RCTs, both of which were small, CBT did not outperform the comparison conditions (Catani et al., 2009; Shirk et al., 2014). In Catani et al. (2009), a brief, six-session CBT and a meditation-relaxation intervention resulted in similar symptom reduction. Shirk et al. (2014) found no differences between CBT and usual care, but the inclusion criteria differed somewhat compared with most other studies in this review (i.e., primary diagnosis of depression, with trauma-related symptoms vs. PTSS), and both conditions had poor attendance.

Strengths of the research conducted since the Silverman et al. (2008) review include evidence of effectiveness for other individual CBT approaches beyond TF-CBT. For example, in one of the PE-A RCTs, the effect size for PTSS was double that of the comparison condition (e.g., Foa et al., 2013). These studies also contribute to the effectiveness of CBT with culturally and ethnically diverse youth, including African Americans in the United States (Salloum \& Overstreet, 2008), Israeli (Aderka et al., 2011; Gilboa-Schechtman et al., 2010) and Sri Lankan youth (Catani et al., 2009), and refugee youth in Germany (Ruf et al., 2010). Another advance is the examination of effectiveness in usual care settings.

However, research on interventions in this treatment family, both from the 2008 review and the eight new studies, mostly involved small samples (see Deblinger et al., 1996, for an exception) and/or were open trials. Studies conducted in international settings-which provide the bulk of the evidence for effectiveness with diverse youth—were particularly plagued by small samples and/or nonrandomized designs (e.g., Van Der Oord et al., 2010). Both international kidNET RCTs had fewer than 35 participants, and the Israeli PE-A RCT had only 38 participants (Gilboa-Schechtman et al., 2010). Only half of the studies examined effects over a longer term follow-up (i.e., at least 12 months). Those that did were able to demonstrate sustained gains (Aderka et al., 2011; Foa et al., 2013; GilboaSchechtman et al., 2010; Ruf et al., 2010).

Group CBT-One relatively common treatment approach for symptoms of child trauma exposure is providing CBT via group therapy, in which children and adolescents are the exclusive or primary participants (i.e., minimal parent involvement in two or fewer sessions). In group CBT, treatment is of relatively brief duration, generally around 10 sessions, with one approach (Layne et al., 2008) including up to 20 sessions. Groups typically include psychoeducation, coping skills (e.g., relaxation, cognitive coping), and cognitive restructuring. Some approaches include imaginal and/or in vivo exposure, problem solving, or a focus on social support. This treatment approach seems to be commonly tested in school settings, likely due to the greater feasibility of both group-based approaches and approaches that include only youth.

In Silverman et al. (2008), three RCTs of group CBT were included. Two focused on a version of what is now called Cognitive Behavioral Intervention for Children in Schools (CBITS; Kataoka et al., 2003), a treatment previously rated as probably efficacious. CBITS 
includes 10 group sessions and is an approach that includes in vivo and imaginal exposure, as well as some parent involvement (i.e., two psychoeducation-focused sessions). CBITS also includes up to three individual child sessions for imaginal exposure. Notably, CBITS has always been tested with ethnically and culturally diverse children and adolescents, bringing greater confidence for the effectiveness of this approach with diverse youth.

Since the last review, six additional studies that met our review criteria have been published. All were effectiveness studies in school-based settings, with services predominantly delivered by providers located within the schools. Two studies tested CBITS and one tested a CBITS adaptation. The remaining three studies were RCTs that examined alternative group CBT approaches (i.e., not CBITS). Three of the four RCTs tested group CBT compared to WLC (Jaycox et al., 2009) or to an active, CBT comparison condition (Layne et al., 2008; Salloum \& Overstreet, 2008). The fourth RCT tested effectiveness of group CBT with and without imaginal exposure and is discussed separately. Findings from the first three RCTs are mixed.

In the first study (Jaycox et al., 2009), CBT outperformed WLC for PTSS and depression, but the modified version of CBITS that was tested, Support for Students Exposed to Trauma (SSET), had small effect sizes compared to medium (depression) and large (PTSS) effect sizes in the CBITS trials. The authors attributed differences to removing "several of the more clinical elements" (p. 57), including eliminating individual imaginal exposure sessions and parent sessions. However, as the provider type was also different than in CBITS studies (i.e., SSET was designed to ease CBITS delivery by non-mental-health professionals in the schools; see Table 3), reasons for differences in effectiveness cannot be definitively determined. In analyses with a high symptom subgroup, effects for SSET were more pronounced for PTSS and depression. In the two studies that compared CBT to other active treatments, for PTSS and depression, group CBT either outperformed or was equivalent to a universal skills and coping intervention depending on the outcome and analyses (Layne et al., 2008; see Table 3) and was equivalent to an individual CBT approach (Salloum \& Overstreet, 2008). For the subsample for whom grief was examined, CBT outperformed (Layne et al., 2008) the comparison or was equivalent (Salloum \& Overstreet, 2008) to a similar but individually delivered treatment. Positive results at the end of the treatment from two small open trials support these findings (Goodkind, LaNoue, \& Milford, 2010; Morsette, Van Den Pol, Schuldberg, Swaney, \& Stolle, 2012).

One of the most beneficial advancements in the research since Silverman et al. (2008) is additional evidence for treatment effectiveness without explicit, or overt, imaginal exposure (Salloum \& Overstreet, 2012). In group treatment for trauma-related symptoms, imaginal exposure requires some individual sessions or group "pull outs" (Deblinger, Pollio, \& Dorsey, 2016), as exposing children in a group to traumatic memories of other children is not clinically indicated. This can create challenges to the otherwise potentially high efficiency of group work. In the fourth RCT, Salloum and Overstreet (2012) tested group CBT with and without overt imaginal exposure, with similar results across the two conditions. 
The six studies also contribute to increased evidence of effectiveness with culturally and ethnically diverse youth. All of the studies focused on diverse populations-African American (Salloum \& Overstreet, 2008, 2012) and Latino (Jaycox et al., 2009) youth in the United States and predominantly ethnic Muslims in Bosnia (Layne et al., 2008). The two open trials tested CBITS with American Indian children (Goodkind et al., 2010; Morsette et al., 2012), with descriptions of fidelity and cultural adaptation (i.e., involving tribal elders to bring in culturally specific ceremonies and perspectives on trauma and healing). Goodkind et al. (2010) found that PTSS rebounded to pretreatment levels at the 6-month follow-up.

Compared to studies on individual CBT, samples in the four RCTs in this treatment family were larger, all having 50 or more participants. However, group CBT did not consistently outperform active comparison conditions, and attenuated outcomes for SSET raise questions about which aspects of the CBITS modifications—or other factors (e.g., delivery by nonmental-health professionals)—resulted in decreased effectiveness. Thus far, most treatment studies have focused on middle school and high school age children and adolescents. Only two studies in the review (Salloum \& Overstreet, 2008, 2012) examined elementary school age children. There also remains a need to examine effectiveness over time. Only one study examined longer term follow-up (i.e., 12 months; Salloum \& Overstreet, 2012).

\section{Level 2: Probably Efficacious}

Group CBT with Parent Involvement-In the last review by Silverman et al. (2008), two relatively small $(N=44 ; N=55)$ group CBT with parent involvement studies were included (Deblinger, Stauffer, \& Steer, 2001; Kolko, 1996, respectively). In this treatment approach, children and parents typically meet concurrently and separately, with some conjoint activities and sessions. Sessions are longer than in individual CBT (e.g., $2 \mathrm{hr}$ compared to 1), and treatment may last longer (e.g., approximately 16 sessions). Treatment elements are similar to those included in individual CBT with parent involvement and group CBT. However, when the index trauma is physical abuse, treatment focuses as much on parent-level outcomes of parenting behavior and preventing physical abuse recidivism as on addressing mental health sequelae of trauma exposure. Therefore, treatment includes content specific to this goal (i.e., commitment to nonviolence, abuse clarification).

Since the Silverman et al. (2008) review, only two studies that met review criteria were identified—one RCT (Runyon, Deblinger, \& Steer, 2010) and one open trial (Runyon, Deblinger, \& Schroeder, 2009). Both were conducted by the same research group and test Combined Parent-Child Cognitive Behavioral Therapy (Runyon, Ryan, Kolar, \& Deblinger, 2004), a TF-CBT-based approach designed to treat physical abuse. These two studies bolster findings from Silverman et al. (2008) by strengthening the evidence for group CBT with parent involvement when the parent was the perpetrator of physical abuse or was at risk of physical abuse (outcomes were not separated out by substantiation status). However, studies testing this treatment family have been relatively small and have included only a short follow-up (i.e., 3 months; Runyon et al., 2009).

Eye Movement Desensitization and Reprocessing-In the Silverman et al. (2008) review, two small EMDR RCTs were included (Chemtob, Nakashima, \& Carlson, 2002; 
Jaberghaderi, Greenwald, Rubin, Zand, \& Dolatabadi, 2004). EMDR typically includes coping skills (guided imagery, relaxation); cognitive restructuring; imaginal exposure; and, uniquely, simultaneous bilateral sensory input (e.g., eye movement). Treatment typically lasts 8-12 sessions and is conducted in individual therapy. Since the last review, three additional small RCTs investigated the efficacy of EMDR. These studies provide additional evidence for the effectiveness of EMDR compared to WLC (Ahmad, Larsson, \& SundelinWahsten, 2007) and TAU (Farkas, Cyr, Lebeau, \& Lemay, 2010) and similar effectiveness compared to CBT (De Roos et al., 2011). The strength of the evidence for EMDR from the studies included in Silverman et al. (2008) and in this review is limited by small studies (only one had a sample size larger than $50 ; N=52$ ). Of interest, two of the three studies included in this review (De Roos et al., 2011; Farkas et al., 2010) integrated CBT components into EMDR, making it challenging to interpret whether outcomes are due to EMDR-specific elements (i.e., sensory input only); CBT elements; or an overlapping, shared element between the two treatment families (i.e., imaginal exposure). Larger studies that more clearly test the added benefit of EMDR-specific elements (i.e., bilateral sensory input) are needed to advance the empirical basis for this treatment.

\section{Level 3: Possibly Efficacious}

There were no studies of Level 3, 4, or 5 treatment families included in the prior review.

Individual Integrated Therapy for Complex Trauma-Since the prior review, three studies-one RCT (Ford, Steinberg, Hawke, Levine, \& Zhang, 2012), one quasiexperimental study (Kagan, Henry, Trinkle, \& LaFrenier, 2014), and one naturalistic study (Lanktree et al., 2012) — have tested individual integrated therapy for complex trauma. The therapies in this family incorporate various theories, including attachment, developmental, family systems, and CBT within a "complex trauma" framework (see Cook et al., 2005, for more information). Complex trauma is defined by cumulative poly-victimization that is typically interpersonal in nature and involves direct harm, exploitation, or neglect/ abandonment by caregivers (e.g., Courtois \& Ford, 2009). Mental health sequelae of complex trauma are considered to involve greater severity of impairment with higher psychiatric comorbidity, including problems in relationships, self-regulation (e.g., impulse control), and self-endangerment. These interventions prioritize teaching emotion regulation and building positive interpersonal relationships. All were individually delivered, but there was variation in parent involvement and inclusion of exposure. Parent involvement was recommended but not always possible (Kagan et al., 2014; Lanktree et al., 2012) or was not part of the intervention (Ford et al., 2012). Explicit exposure (imaginal and/or in vivo) was included in both Kagan et al. (2014) and Lanktree et al. (2012) but specifically was not included in Ford et al. (2012).

Findings from these studies are mixed. The only RCT (Ford et al., 2012) that tested Trauma Affect Regulation: Guide for Education and Therapy (TARGET) did not obtain a clear picture of benefit over an active treatment comparison condition. TARGET moderately outperformed the enhanced TAU (ETAU) condition for reexperiencing and total PTSS and was similarly effective to ETAU for some outcomes (e.g., depression, hypervigilance), whereas ETAU outperformed TARGET for others (anger, mood regulation expectancies). 
The quasi-experimental study of Real Life Heroes by Kagan et al. (2014) found reductions in varying outcomes assessed at either 6 or 9 months; however, the study had a number of weaknesses. The comparison condition was an inadequately defined TAU (and included only for some, not all, outcomes), treatment was of highly variable duration (1-9 months), and only about one third of youth participated in data collection at 6 months, with only about 10\% participating at 9 months. The naturalistic trial (Lanktree et al., 2012) tested Integrative Treatment of Complex Trauma, a phase-based treatment that can be delivered in highly variable duration depending on client need. Youth who received Integrative Treatment of Complex Trauma demonstrated clinical improvement in PTSS, depression, anxiety, and other outcomes for youth over time. However, as a naturalistic study, it did not include a control group.

Group Mind-Body Skills-Two studies (one RCT, one open trial) examined mind-body skills groups that combine mindfulness, meditation, relaxation, guided imagery, and biofeedback. Both studies tested the intervention with war-affected youth. Together, these studies provide some evidence for the effectiveness of the intervention in reducing PTSS compared to WLC for adolescents in Kosovo (Gordon, Staples, Blyta, Bytyqi, \& Wilson, 2008), with maintenance at a 3-month follow-up. Results from the RCT are somewhat supported by a large open trial conducted in Gaza (Staples, Atti, \& Gordon, 2011; $N=129$ ), although PTSS and depression rebounded at the 3-month follow-up.

\section{Level 4: Experimental}

Individual Client-Centered Play Therapy-In a small RCT with refugee and immigrant children, neither individual client-centered play therapy nor TF-CBT (the comparison condition) resulted in symptom improvement (Schottelkorb, Doumas, \& Garcia, 2012), except in analyses with a clinically severe subsample. These findings are in contrast to studies supporting TF-CBT in earlier sections. However, in this study, the population of focus was different (i.e., refugee children), and there were alterations in TF-CBT in both delivery (i.e., 30-min sessions) and parent involvement (i.e., only two sessions; see Table 3).

Individual Mind-Body Skills-One small RCT (Catani et al., 2009; $N=31$ ) reviewed earlier in the Child Individual CBT section tested an individual mind-body skills approach based in meditation and relaxation as the comparison group for the predominantly exposurebased child CBT model (i.e., kidNET), with similar posttreatment and 6-month follow-up outcomes between the two conditions.

Individual Psychoanalysis-A small open trial (Nilsson \& Wadsby, 2010; $N=15$ ) tested a child individual psychoanalytic approach, Symboldrama, with Swedish adolescents. The intervention focused on guided imagery and visualization. Significant pre to post differences were found for dissociation, anxiety, depression, anger, and PTSS, with no differences for sexual concerns.

\section{Level 5: Questionable Efficacy}

Group Creative Expressive + CBT-Two large, international cluster RCTs (Tol et al., 2014, 2008) examined a group-based, child-only creative and expressive activities-based 
intervention-Classroom-Based Intervention (CBI)—delivered in schools compared to WLC for war-exposed youth. CBI integrated creative and expressive activities (e.g., cooperative games, drama, music, dance) with CBT (e.g., psychoeducation, coping skills, some imaginal exposure via drawing). CBI was largely ineffective in both studies. In the first RCT (Tol et al., 2008), PTSS were improved at the end of treatment and a 6-month followup. However, there were no other significant differences on outcomes examined (e.g., depression, aggression, functioning) in the first RCT (Tol et al., 2008), and there were no main intervention effects on any outcomes examined (i.e., PTSS, depression, or functioning) in the second RCT (Tol et al., 2014). In explaining the lack of effectiveness in both studies, the authors cited methodological or design problems (Tol et al., 2008), baseline symptom differences between the conditions (Tol et al., 2014), insufficiently rigorous fidelity assessment, and/or that CBT elements were not delivered in a sufficient dose.

Moderators and Mediators of Treatment Response-The trauma treatment studies included in this review infrequently examined mediators and moderators of treatment, likely due to small sample sizes that may have prohibited these analyses. Studies frequently controlled for the effects of potential moderators (e.g., Danielson et al., 2012; Scheeringa et al., 2011) but did not test for moderation effects. This section focuses only on moderators for well-established and probably efficacious treatment families, of which there were very few.

With only one exception (Salloum \& Overstreet, 2008), in which younger girls showed less improvement in PTSS, demographic characteristics of child age and sex did not moderate treatment outcomes (Cohen et al., 2011; Deblinger et al., 2011; Murray et al., 2013; Salloum \& Overstreet, 2008, 2012). Six other moderators were examined: cumulative trauma exposure (Murray et al., 2013), maternal PTSD symptoms, parental functioning (Nixon et al., 2012), treatment dose (Deblinger et al., 2011), explicit exposure (Deblinger et al., 2011; Nixon et al., 2012; Salloum \& Overstreet, 2012), treatment modality (Salloum \& Overstreet, 2008), and sudden gains (Aderka et al., 2011). Among these, only four were significant: parental functioning, treatment dose, explicit exposure, and sudden gains. In the area of parental functioning, maternal depressive symptoms and unhelpful trauma-related beliefsbut not maternal PTSS - moderated children's response to treatment in one study (Nixon et al., 2012). In another, maternal PTSS moderated outcomes for child anxiety but not for PTSS (Weems \& Scheeringa, 2013). Treatment dose moderated outcomes, with longer treatment (16 vs. 8 sessions) more effective in reducing avoidance and reexperiencing symptoms of PTSS (Deblinger et al., 2010). In three dismantling studies examining explicit exposure as a moderator, findings were mixed. Explicit exposure did not moderate outcomes for PTSS or depressive symptoms in any of the studies (Deblinger et al., 2011; Nixon et al., 2012; Salloum \& Overstreet, 2012) but did moderate outcomes for general anxiety (Deblinger et al., 2011; Nixon et al., 2012), fear associated with talking or thinking about the abuse (Deblinger et al., 2011), and behavioral problems (Deblinger et al., 2011) at the end of treatment. Conditions with explicit exposure resulted in better outcomes for general anxiety and fear and less positive outcomes for behavior problems (Deblinger et al., 2011); however, differences disappeared by the 6- and 12-month follow-ups. Of interest, sudden gains influenced treatment outcomes: Participants with sudden gains had larger overall improvements in PTSS and depressive symptoms (Aderka et al., 2011). 
Looking beyond studies included in this review, Silverman et al. (2008) noted other aspects of parental functioning that moderated outcomes, including parental emotional reaction to the child's sexual abuse (Cohen \& Mannarino, 1996, 2000) and parental support (Cohen \&Mannarino, 2000). In objective coding of TF-CBT therapy sessions, Ready et al. (2015) found that high levels of accommodated, trauma-related beliefs ("I know now it wasn't my fault") moderated the relation between over-generalized beliefs (e.g., "Nothing is safe") and poorer treatment outcomes, particularly for younger children. In other reviews conducted during the 2008-2014 period (see Table 1), the lack of focus on mediators and moderators was noted, largely attributed to small samples. In a meta-analysis focused specifically on treatment of children exposed to sexual abuse, Trask, Walsh, and DiLillo (2011) found that none of the examined moderators were significant (i.e., child characteristics [i.e., age, sex, ethnicity], caregiver involvement, treatment modality).

\section{DISCUSSION}

Considerable evidence regarding the efficacy of psychosocial treatments for youths with mental health symptoms related to trauma exposure has been generated since the Silverman et al. review in 2008, with a total of 37 studies included in this evidence base update. Consistent with findings from Silverman et al., results provide evidence for CBT as the recommended first-line treatment approach given that all but one of the treatments in the well-established (Level 1) and probably efficacious (Level 2) evidence categories were CBT. However, outcomes for CBT were not universally positive (see Shirk et al., 2014; Schottelkorb et al., 2012, for examples). The only other treatment rated in the top two levels, EMDR, included CBT elements in two of the three studies reviewed. Providing additional confidence in CBT as the recommended approach, comparison conditions for RCTs included in this review were typically active treatments and not WLC (13 of 15 RCTs on CBT; 80\%). In contrast, non-CBT treatments (including EMDR) have received less research attention, and the few existing studies that met review criteria tended to have more methodological weaknesses (e.g., small sample sizes, nonrandomized designs).

Although the overall message from this review supports findings from Silverman et al. (2008), the review offers important advancements, including evidence for multiple versions of CBT (e.g., with and without parent involvement, non-TF-CBT based approaches, approaches with and without explicit exposure, group and individual modalities) and greater attention to external validity (e.g., diverse samples, trials in community-based settings).

\section{Well-Established Treatments: Common Elements}

Almost all of the individual interventions within the well-established treatment families, the highest evidentiary category, included some combination of these six elements: (a) psychoeducation about trauma prevalence, impact, and the intervention; (b) training in emotion regulation strategies (e.g., relaxation, identification of emotion, cognitive coping); (c) imaginal exposure; (d) in vivo exposure; (e) cognitive processing; and/or (f) problem solving. These findings are consistent with Chorpita and Daleiden's (2009) distillation and mapping work identifying "practice elements" for PTSS. Most CBT interventions were similar in structure (e.g., practice of learned skills) and dose of delivery (e.g., consisted of 
approximately 10-20 sessions; range $=4-23$ ). However, the specific emphasis of the individual interventions varied. Some were multicomponent with equal emphasis on emotion regulation skills to cope with trauma reminders, imaginal and/or in vivo exposure, and cognitive processing (e.g., CBITS, TF-CBT). Others delivered predominantly imaginal exposure (e.g., PE-A, kidNET) or cognitive processing (cognitive therapy; Nixon et al., 2012). Some were delivered individually (TF-CBT) and some via group format (CBITS). Findings from our review suggest that within the broad treatment category of CBT, providers, organizations, and policymakers likely have substantial room to incorporate provider and client choice about which particular treatment to use, within trauma-focused CBTs. Of course, not all individual treatments within a treatment family have the same amount of empirical support. Some individual interventions, like CBITS and TF-CBT, have received more research attention. Two particular areas in which client and provider preference may drive decisions, until clearer empirical guidance is available, are parent involvement and inclusion of explicit exposure.

Is Parent Involvement Necessary? - The multiple versions of CBT vary with regard to parent involvement. Whether parents need to be involved in treatment continues to be a debated issue in the field (e.g., Leenarts, Diehle, Dorelejiers, Jansma, \& Lindauer, 2013). At the time of the Silverman et al. (2008) review, the only well-established treatment-TF-CBT -included substantial parent involvement. However, across the 21 RCTs included in their review, meta-analyses indicated that parent involvement was not critical for most outcomes (Silverman et al., 2008). Given the small number of studies (i.e., 21); however, analyses did not distinguish type of treatment (CBT vs. other) or extent of parental involvement (e.g., some parent involvement studies may have included very minimal involvement). In the area of anxiety, parent involvement typically improves the use of coping skills and other strategies but is not associated with significantly greater symptom reduction (Mendlowitz et al., 1999; Spence, Donovan, \& Brechman-Toussaint, 2000). Treatment of trauma-related anxiety may be different, considering findings that parental mental health, support, emotional reaction to and unhelpful beliefs about trauma exposure moderated some important outcomes for children (Cohen \& Mannarino, 1996, 2000; Nixon et al., 2012; Weems \& Scheeringa, 2013). In a study employing objective, process coding of TF-CBT sessions (Yasinski et al., 2016), parental cognitive-emotional processing and emotional support predicted improvement in child internalizing symptoms, whereas parental avoidance and child blame predicted worse externalizing symptoms.

Our review suggests that including parents and other caregivers in treatment is still empirically supported; however, two of the three well-established treatment families in this review included minimal or no parent involvement (at least for children 7 and older), with relatively similar outcomes. This finding offers some hope for situations in which parent involvement is challenging (e.g., school-based services). The moderator analyses provide some guidance about situations when treatment should include parents, including when children are young (ages 3-6; Scheeringa et al., 2011), when children have behavioral problems (Deblinger et al., 1996; Deblinger et al., 2010), when parents were perpetrators themselves (Runyon et al., 2010), and when parents have their own mental health problems (Weems \& Scheeringa, 2013) and/or unhelpful trauma-related beliefs (Nixon et al., 2012). 
To definitively answer the question about parent involvement, more studies that specifically examine parent characteristics and other potential child-level moderators (e.g., child age, comorbid externalizing problems) are needed.

Is Trauma Narration Required?-Whether explicit exposure-imaginal, in vivo, or both-is required continues to be another debate in the field. Since the Silverman et al. (2008) review, three studies have specifically examined this question. In each study, children were randomized to treatment either with or without imaginal exposure (Deblinger et al., 2011; Salloum \& Overstreet, 2012) or with and without imaginal and in vivo exposure (Nixon et al., 2012). However, participants in conditions without exposure still received a "trauma-focused" treatment with low-level, general exposure through other elements (e.g., psychoeducation, planning for emotion regulation when facing trauma reminders and triggers), and, in Nixon et al. (2012), cognitive processing of trauma-related thoughts. Findings from these studies suggest that explicit exposure may not be necessary. These findings are relatively consistent with two adult studies focused on a similar question (Foa et al., 1999; Resick et al., 2008). Explicit exposure is one of the elements with which clinicians often are most uncomfortable and may be one they are least likely to deliver (Borntrager, Chorpita, Higa-McMillen, Daleiden, \& Starace, 2013; McLeod \& Weisz, 2010). If explicit exposure is not required, CBT interventions may be more palatable to both clinicians and some clients.

\section{Generalizability and Representativeness}

When considering the generalizability of treatments for symptoms related to trauma exposure, the glass is both half-full and half-empty. In the area of external validity, the literature has progressed more quickly than for many other treatment areas. Compared to other reviews in this evidence base update series, studies focused on sequelae of trauma exposure included highly diverse ethnic and cultural groups in the United States, as well as diverse international youth both in their home countries (e.g., Bosnia, Norway) and in other settings as immigrants or refugees. The international studies included both high-income (Jensen et al., 2014) and low-income (Murray et al., 2013) countries. Potential external validity of these interventions is strengthened by a greater focus on effectiveness research and the utilization of a deployment-focused model (Weisz, 2004) in which interventions are tested in "end goal" delivery settings (e.g., schools, public mental health clinics) with providers who would be likely to deliver these interventions if they were scaled up for population-level reach (Weisz, Southam-Gerow, Gordis, \& Connor-Smith, 2003). Finally, studies included children and adolescents exposed to a wide range of traumatic events (see Table 3; interpersonal violence, war, physical abuse), many with poly-victimization.

In the area of internal validity, one improvement since Silverman et al. (2008) is that studies included in this review provided at least basic details on training and supervision processes (e.g., manual used, supervision frequency and by whom) to support treatment integrity. However, few evaluated treatment fidelity or integrity (see Southam-Gerow \& McLeod, 2013), and even fewer used rigorous objective methods (e.g., masked coders using standardized coding systems). Rigor of integrity measurement was also, for the most part, confounded with setting and providers in that studies conducted in community settings were 
less likely to evaluate integrity (see Jaycox et al., 2009, for an exception). As Schoenwald (2011) and others have stated, research methods for fidelity monitoring fit poorly with community practice, but evaluations of treatment integrity are critical for making sense of study outcomes.

Although there have been advancements, the literature on treatment for trauma-related symptoms continues to be plagued by studies comprising small sample sizes, particularly for culturally diverse groups. Of the RCTs included in this review and in the Silverman review, 21 of $48(43.75 \%)$ had sample sizes of 50 or fewer participants; 37 of $48(77.08 \%)$ had sample sizes of 100 or fewer. In addition to small samples, studies cannot definitively attribute symptoms treated in these studies to trauma exposure (as opposed to attributing these symptoms to preexisting mental health problems). Most treatments seemed to target PTSS, as in Silverman et al. (2008), but often assessed a wide range of other outcomes. Only some authors differentiated between primary and secondary outcomes (e.g., Salloum \& Overstreet, 2012).

Another limitation of the current evidence base noted in the prior review (and sometimes related to sample size) is analytical appropriateness. Too few studies included clinically meaningful analyses, such as effect sizes or reliable change indices. Most relied on statistical tests of mean differences. Compared to the past review, twice as many studies in this review examined outcomes using intent-to-treat analyses ( 3 of 21; 14\% in Silverman et al., 2008; 11 of $37 ; 29.73 \%$ in this review). However, most reported results for completer and not intentto-treat analyses (see Salloum \& Overstreet, 2008, for an exception). In addition, many of the studies included multiple sites and providers, but very few used a nested data analysis structure to examine site- or provider-level differences that might account for findings. Finally, the small sample sizes in most studies precluded examination of mediators and moderators of treatment.

\section{Limitations of This Review}

Our goal was to meet the objectives of this series of evidence base update reviews, which focus on treatment for specific problems (Southam-Gerow \& Prinstein, 2014). Therefore, we made the decision to focus our review specifically on studies that selected participants who themselves reported trauma exposure and specific elevated mental health symptoms (by selfand/or parent-report). Studies that did not assess trauma exposure, but were conducted in areas of likely high trauma exposure (e.g., postnatural disaster areas), were not included. Similarly, and sometimes overlapping, some studies did not assess each child's mental health symptoms as a criterion for study/treatment inclusion (e.g., O'Callaghan, McMullen, Shannon, Rafferty, \& Black, 2013; Swenson, Schaeffer, Henngeler, Faldowski, \& Mayhew, 2010). This resulted in the exclusion of a large number of studies. We also excluded studies that were more focused on trauma-informed treatments versus trauma-focused treatments. Increasingly, trauma-informed practices and trauma-informed systems are growing in popularity, with, to our knowledge, very limited empirical support. This area would benefit from a thorough review. Finally, we did not search for and include unpublished literature or studies published in a language other than English. 


\section{Future Directions}

Based on our review, the primary future direction is to focus research efforts on conducting more rigorous studies that involve dismantling multicomponent interventions to provide better empirical guidance on necessary treatment elements and who needs to participate in treatment (e.g., youth only, youth and parents). To better determine what works for whom, studies should ideally include samples large enough to examine mediators and moderators of treatment. Based on our review, it seems that some treatment elements may be comparably effective (e.g., imaginal exposure vs. cognitive processing), but empirical studies are needed both to simplify treatment and to give providers options, which may assist with their engagement in delivering EBTs (Borntrager et al., 2013). Particularly for community mental health, where dropout rates are high (e.g., Miller, Southam-Gerow, \& Allin, 2008), simplifying treatment approaches and determining the necessary dose for different types of children and adolescents would be beneficial. A recent study (Wamser-Nanney, Scheeringa, \& Weems, 2014) of individually delivered child and parent CBT demonstrated that some children were early responders after four sessions and that early treatment response was maintained. Determining alternative delivery approaches also is important (see Salloum et al., 2014, for an example).

However, the biggest challenge in trauma treatment is not determining which elements are required, necessary treatment dose, or even mediators or moderators. Instead, as in other areas of mental health and health care generally, the challenge is how to implement and sustain any intervention with evidence of efficacy or effectiveness. Even basic behavioral change like provider hand washing in hospital care settings is difficult to implement and sustain (e.g., Squires et al., 2013). Complicated, multicomponent interventions present even greater challenges. When population-level impact is considered, interventions that are more feasible-even when less effective - can have substantially greater reach (see Zatzick, Koepsell, \& Rivara, 2009, for an example). This review highlights that trauma treatment has made substantial progress since 2008, with innovative work ongoing (e.g., Wamser-Nanney et al., 2014). The challenge moving forward will be to balance the field's focus on what works for whom, with challenges of implementation and dissemination, population reach, and public health impact.

\section{Acknowledgments}

We gratefully acknowledge the contributions of Lucy Berliner, Harborview Center for Sexual Assault and Traumatic Stress; Shannon Wiltsey-Stirman, Palo Alto Veterans Affairs Healthcare System and Stanford Medicine; and Kate Benjamin, Shanon Cox, Lucy Dong, Jessica Garcia, Andy Pendergrass, Meilin Jia-Richards, Leah Lucid, Zoe Miles, Eliza Segell, Jessica Silbaugh-Cowdin, Kelly Thompson, Stephanie Violante, and Kelsey Walker at the University of Washington.

\section{FUNDING}

This publication was made possible in part by funding from grant numbers R01MH095749 and R01MH96633 (Dorsey, PI/MPI) and K01 MH092526 and R01 MH103291 (McLaughlin, PI/MPI), awarded from the National Institute of Mental Health.

Dr. Dorsey is an investigator with the Implementation Research Institute, at the George Warren Brown School of Social Work, Washington University in St. Louis; through an award from the National Institute of Mental Health (R25 MH080916) and the Department of Veterans Affairs, Health Services Research \& Development Service, Quality Enhancement Research Initiative.

J Clin Child Adolesc Psychol. Author manuscript; available in PMC 2017 May 01. 


\section{REFERENCES}

Aderka IM, Appelbaum-Namdar E, Shafran N, Gilboa-Schechtman E. Sudden gains in prolonged exposure for children and adolescents with posttraumatic stress disorder. Journal of Consulting and Clinical Psychology. 2011; 79(4):441-446. [PubMed: 21787047]

Ahmad A, Larsson B, Sundelin-Wahlsten V. EMDR treatment for children with PTSD: Results of a randomized controlled trial. Nordic Journal of Psychiatry. 2007; 61(5):349-354. [PubMed: 17990196]

American Psychiatric Association. Diagnostic and statistical manual of mental disorders. 4th. Washington, DC: Author; 1994.

Benjet C, Borges G, Medina-Mora ME, Zambrano J, Cruz C, Méndez E. Descriptive epidemiology of chronic childhood adversity in Mexican adolescents. Journal of Adolescent Health. 2009; 45:483489. [PubMed: 19837355]

Borntrager C, Chorpita BF, Higa-McMillan CK, Daleiden EL, Starace N. Usual care for traumaexposed youth: Are clinician-reported therapy techniques evidence-based? Children and Youth Services Review. 2013; 35(1):133-141.

Breslau N, Kessler RC, Chilcoat HD, Schultz LR, Davis GC, Andreski P. Trauma and posttraumatic stress disorder in the community: The 1996 Detroit area survey of trauma. Archives of General Psychiatry. 1998; 55:626-632. [PubMed: 9672053]

Cary CE, McMillen JC. The data behind the dissemination: A systematic review of trauma-focused cognitive behavioral therapy for use with children and youth. Children and Youth Services Review. 2012; 34:748-757.

Catani C, Kohiladevy M, Ruf M, Schauer E, Elbert T, Neuner F. Treating children traumatized by war and tsunami: A comparison between exposure therapy and meditation-relaxation in North-East Sri Lanka. BMC Psychiatry. 2009; 9(1):1-19. [PubMed: 19133132]

Chambless DL, Baker MJ, Baucom DH, Beutler LE, Calhoun KS, Crits-Cristoph P, Woody SR. Update on empirically validated therapies, II. The Clinical Psychologist. 1998; 51(1):3-16.

Chambless DL, Hollon SD. Defining empirically supported therapies. Journal of Consulting and Clinical Psychology. 1998; 66(1):7. [PubMed: 9489259]

Chambless DL, Ollendick TH. Empirically supported psychological interventions: Controversies and evidence. Annual Review of Psychology. 2001; 52(1):685-716.

Chambless DL, Sanderson WC, Shoham V, Bennett Johnson S, Pope KS, Crits-Cristoph P, McCurry S. An update on empirically validated therapies. The Clinical Psychologist. 1996; 49(2):5-18.

Chemtob C, Nakashima J, Carlson J. Brief treatment for elementary school children with disasterrelated posttraumatic stress disorder: A field study. Journal of Clinical Psychology. 2002; 58:99112. [PubMed: 11748599]

Chorpita BF, Daleiden EL. Mapping evidence-based treatments for children and adolescents: Application of the distillation and matching model to 615 treatments from 322 randomized trials. Journal of Consulting and Clinical Psychology. 2009; 77(3):566-579. [PubMed: 19485596]

Cohen JA, Mannarino AP. A treatment outcome study for sexually abused preschool children: Initial findings. Journal of the American Academy of Child \& Adolescent Psychiatry. 1996; 35(1):42-50. [PubMed: 8567611]

Cohen JA, Mannarino AP. A treatment study for sexually abused preschool children: Outcome during a one-year follow-up. Journal of the American Academy of Child \& Adolescent Psychiatry. 1997; 36(9):1228-1235. [PubMed: 9291724]

Cohen JA, Mannarino AP. Predictors of treatment outcome in sexually abused children. Child Abuse \& Neglect. 2000; 24(7):983-994. [PubMed: 10905421]

Cohen, JA., Mannarino, AP., Deblinger, E. Treating trauma and traumatic grief in children and adolescents. New York, NY: Guilford; 2006.

Cohen JA, Mannarino AP, Iyengar S. Community treatment of posttraumatic stress disorder for children exposed to intimate partner violence: A randomized controlled trial. Archives of Pediatrics \& Adolescent Medicine. 2011; 165:16-21. [PubMed: 21199975] 
Cohen JA, Mannarino AP, Perel JM, Staron V. A pilot randomized controlled trial of combined trauma-focused CBT and sertraline for childhood PTSD symptoms. Journal of the American Academy of Child \& Adolescent Psychiatry. 2007; 46:811-819. [PubMed: 17581445]

Cook A, Spinazzola J, Ford J, Lanktree C, Blaustein M, Cloitre M, Van Der Kolk B. Complex trauma in children and adolescents. Psychiatric Annals. 2005; 35(5):390-398.

Copeland WE, Keeler G, Angold A, Costello EJ. Traumatic events and posttraumatic stress in childhood. Archives of General Psychiatry. 2007; 64(5):577-584. [PubMed: 17485609]

Courtois, CA., Ford, JD., editors. Treating complex traumatic stress disorders: An evidence-based guide. New York, NY: Guilford Press; 2009.

Danielson CK, McCart MR, De Arellano MA, Macdonald A, Doherty LS, Resnick HS. Risk reduction for substance use and trauma-related psychopathology in adolescent sexual assault victims: Findings from an open trial. Child Maltreatment. 2010; 15:261-268. [PubMed: 20534594]

Danielson CK, McCart MR, Walsh K, De Arellano MA, White D, Resnick HS. Reducing substance use risk and mental health problems among sexually assaulted adolescents: A pilot randomized controlled trial. Journal of Family Psychology. 2012; 26:628-635. [PubMed: 22686269]

De Arellano MA, Lyman DR, Jobe-Shields L, George P, Dougherty RH, Daniels AS, Delphin-Rittmon ME. Trauma-focused cognitive-behavioral therapy for children and adolescents: Assessing the evidence. Psychiatric Services. 2014; 65(5):591-602. [PubMed: 24638076]

De Bellis MD, Hooper SR, Woolley DP, Shenk CE. Demographic, maltreatment, and neurobiological correlates of PTSD symptoms in children and adolescents. Journal of Pediatric Psychology. 2010; 35:570-577. [PubMed: 20008084]

De Roos C, Greenwald R, Den Hollander-Gijsman M, Noorthoorn E, Van Buuren S, De Jongh A. A randomised comparison of cognitive behavioural therapy (CBT) and eye movement desensitisation and reprocessing (EMDR) in disaster-exposed children. European Journal of Psychotraumatology. 2011; 2:1-11.

Deblinger E, Lippmann J, Steer R. Sexually abused children suffering posttraumatic stress symptoms: Initial treatment outcome findings. Child Maltreatment. 1996; 1(4):310-321.

Deblinger E, Mannarino AP, Cohen JA, Runyon MK, Steer RA. Trauma-focused cognitive behavioral therapy for children: Impact of the trauma narrative and treatment length. Depression and Anxiety. 2010; 28(1):67-75. [PubMed: 20830695]

Deblinger E, Pollio E, Dorsey S. Applying trauma-focused cognitive-behavioral therapy in group format. Child Maltreatment. 2016; 2:59-73.

Deblinger E, Stauffer LB, Steer RA. Comparative efficacies of supportive and cognitive behavioral therapies for young children who have been sexually abused and their nonoffending mothers. Child Maltreatment. 2001; 6(4):332-343. [PubMed: 11675816]

Dorsey S, Briggs EC, Woods BA. Cognitive-behavioral treatment for posttraumatic stress disorder in children and adolescents. Child and Adolescent Psychiatric Clinics of North America. 2011; 20:255-269. [PubMed: 21440854]

Dowd H, McGuire BE. Psychological treatment of PTSD in children: An evidence-based review. The Irish Journal of Psychology. 2011; 32:25-39.

Farkas L, Cyr M, Lebeau TM, Lemay J. Effectiveness of MASTR EMDR therapy for traumatized adolescents. Journal of Child \& Adolescent Trauma. 2010; 3(2):125-142.

Finkelhor D, Ormrod R, Turner HA. The developmental epidemiology of childhood victimization. Journal of Interpersonal Violence. 2009; 24:711-731. [PubMed: 18467689]

Foa EB, Dancu CV, Hembree EA, Jaycox LH, Meadows EA, Street GP. A comparison of exposure therapy, stress inoculation training, and their combination for reducing posttraumatic stress disorder in female assault victims. Journal of Consulting and Clinical Psychology. 1999; 67(2): 194-200. [PubMed: 10224729]

Foa EB, McLean CP, Capaldi S, Rosenfield D. Prolonged exposure vs supportive counseling for sexual abuse-related PTSD in adolescent girls: A randomized clinical trial. Journal of the American Medical Association. 2013; 310(24):2650-2657. [PubMed: 24368465]

Foa EB, Meadows EA. Psychosocial treatments for posttraumatic stress disorder: A critical review. Annual Review of Psychology. 1997; 48:449-480. 
Ford JD, Grasso D, Greene C, Levine J, Spinazzola J, Van Der Kolk B. Clinical significance of a proposed developmental trauma disorder diagnosis: Results of an international survey of clinicians. The Journal of Clinical Psychiatry. 2013; 74(8):841-849. [PubMed: 24021504]

Forman-Hoffman VL, Zolotor AJ, McKeeman JL, Blanco R, Knauer SR, Lloyd SW, Viswanathan M. Comparative effectiveness of interventions for children exposed to nonrelational traumatic events. Pediatrics. 2013; 131(3):526-539. [PubMed: 23400617]

Fraser JG, Lloyd S, Murphy R, Crowson M, Zolotor AJ, Cocker-Schwimmer E, Viswanathan M. A comparative effectiveness review of parenting and trauma-focused interventions for children exposed to maltreatment. Journal of Developmental \& Behavioral Pediatrics. 2013; 34(5):353368. [PubMed: 23588113]

Giaconia RM, Reinherz HZ, Silverman AB, Pakiz B, Frost AK, Cohen E. Traumas and posttraumatic stress disorder in a community population of older adolescents. Journal of the American Academy of Child \& Adolescent Psychiatry. 1995; 34(10):1369-1380. [PubMed: 7592275]

Gilboa-Schechtman E, Foa EB, Shafran N, Aderka IM, Powers MB, Rachamim L, Apter A. Prolonged exposure versus dynamic therapy for adolescent PTSD: A pilot randomized controlled trial. Journal of the American Academy of Child and Adolescent Psychiatry. 2010; 49(10):1034-1042. [PubMed: 20855048]

Gillies D, Taylor F, Gray C, O'Brien L, D'Abrew N. Psychological therapies for the treatment of posttraumatic stress disorder in children and adolescents. Evidence-Based Child Health: A Cochrane Review Journal. 2012; 8:1004-1116.

Goodkind JR, LaNoue MD, Milford J. Adaptation and implementation of cognitive behavioral intervention for trauma in schools with American Indian youth. Journal of Clinical Child \& Adolescent Psychology. 2010; 39(6):858-872. [PubMed: 21058132]

Gordon JS, Staples JK, Blyta A, Bytyqi M, Wilson AT. Treatment of posttraumatic stress disorder in postwar Kosovar adolescents using mind-body skills groups: A randomized controlled trial. The Journal of Clinical Psychiatry. 2008; 69:1469-1476. [PubMed: 18945398]

Harvey ST, Taylor JE. A meta-analysis of the effects of psychotherapy with sexually abused children and adolescents. Clinical Psychology Review. 2010; 30:517-535. [PubMed: 20417003]

Jaberghaderi N, Greenwald R, Rubin A, Zand SO, Dolatabadi S. A comparison of CBT and EMDR for sexually abused Iranian girls. Clinical Psychology and Psychotherapy. 2004; 11:358-368.

Jaycox LH, Langley AK, Stein BD, Wong M, Sharma P, Scott M, Schonlau M. Support for students exposed to trauma: A pilot study. School Mental Health. 2009; 1(2):49-60. [PubMed: 20811511]

Jensen TK, Holt T, Ormhaug SM, Egeland K, Granly L, Hoaas LC, Wentzel-Larsen T. A randomized effectiveness study comparing trauma-focused cognitive behavioral therapy with therapy as usual for youth. Journal of Clinical Child \& Adolescent Psychology. 2014; 43(3):356-369. [PubMed: 23931093]

Jordans MJD, Tol WA, Komproe IH, De Jong JVTM. Systematic review of evidence and treatment approaches: Psychosocial and mental health care for children in war. Child and Adolescent Mental Health. 2009; 14:2-14.

Kagan R, Henry J, Richardson M, Trinkle J, LaFrenier A. Evaluation of real life heroes treatment for children with complex PTSD. Psychological Trauma: Theory, Research, Practice, and Policy. 2014; 6(5):588-596.

Kataoka SH, Stein BD, Jaycox LH, Wong M, Escudero P, Tu W, Fink A. A school-based mental health program for traumatized Latino immigrant children. Journal of the American Academy of Child and Adolescent Psychiatry. 2003; 42(3):311-318. [PubMed: 12595784]

Kilpatrick DG, Ruggiero KJ, Acierno R, Saunders BE, Resnick HS, Best CL. Violence and risk of PTSD, major depression, substance abuse/dependence, and comorbidity: Results from the National Survey of Adolescents. Journal of Consulting and Clinical Psychology. 2003; 71:692-700. [PubMed: 12924674]

King NJ, Tonge BJ, Mullen P, Myerson N, Heyne D, Rollings S, Ollendick TH. Treating sexually abused children with posttraumatic stress symptoms: A randomized clinical trial. Journal of the American Academy of Child \& Adolescent Psychiatry. 2000; 39(11):1347-1355. [PubMed: 11068889] 
Kolko DJ. Individual cognitive behavioral treatment and family therapy for physically abused children and their offending parents: A comparison of clinical outcomes. Child Maltreatment. 1996; 1:322342.

Kowalik J, Weller J, Venter J, Drachman D. Cognitive Behavioral Therapy for the treatment of pediatric posttraumatic stress disorder: A review and meta-analysis. Journal of Behavior Therapy and Experimental Psychiatry. 2011; 42:405-413. [PubMed: 21458405]

Lanktree CB, Briere J, Godbout N, Hodges M, Chen K, Trimm L, Freed W. Treating multitraumatized, socially marginalized children: Results of a naturalistic treatment outcome study. Journal of Aggression, Maltreatment \& Trauma. 2012; 21(8):813-828.

Layne CM, Saltzman WR, Poppleton L, Burlingame GM, Pašalić A, Duraković E, Pynoos RS. Effectiveness of a school-based group psychotherapy program for war-exposed adolescents: A randomized controlled trial. Journal of the American Academy of Child \& Adolescent Psychiatry. 2008; 47(9):1048-1062. [PubMed: 18664995]

Leenarts L, Diehle J, Dorelejiers T, Jansma E, Lindauer R. Evidence-based treatments for children with trauma-related psychopathology as a result of childhood maltreatment: A systematic review. European Child \& Adolescent Psychiatry. 2013; 22:269-283. [PubMed: 23266844]

Leskin LP, White PM. Attentional networks reveal executive function deficits in posttraumatic stress disorder. Neuropsychology. 2007; 21:275-284. [PubMed: 17484590]

Macdonald G, Higgins, Ramchandani P, Valentine JC, Bronger LP, Klein P, Taylor M. Cognitivebehavioural interventions for children who have been sexually abused. Cochrane Database of Systematic Reviews. 2012; 5:CD001930.

Mannarino AP, Cohen JA, Deblinger E, Runyon MK, Steer RA. Trauma-focused cognitive-behavioral therapy for children sustained impact of treatment 6 and 12 months later. Child Maltreatment. 2012; 17(3):231-241. [PubMed: 22763575]

McLaughlin KA, Koenen KC, Hill E, Petukhova M, Sampson NA, Zaslavsky A, Kessler RC. Trauma exposure and post-traumatic stress disorder in a US national sample of adolescents. Journal of the American Academy of Child \& Adolescent Psychiatry. 2013; 52:815-830. [PubMed: 23880492]

McLeod BD, Weisz JR. The therapy process observational coding system for child psychotherapystrategies scale. Journal of Clinical Child \& Adolescent Psychology. 2010; 39(3):436-443. [PubMed: 20419583]

Mendlowitz SL, Manassis K, Bradley S, Scapillato D, Miezitis S, Shaw BF. Cognitive-behavioral group treatments in childhood anxiety disorders: The role of parental involvement. Journal of the American Academy of Child \& Adolescent Psychiatry. 1999; 38(10):1223-1229. [PubMed: 10517054]

Miller LM, Southam-Gerow MA, Allin RB. Who stays in treatment? Child and family predictors of youth client retention in a public mental health agency. Child \& Youth Care Forum. 2008; 37:153170. [PubMed: 19774098]

Misurell J, Springer C, Acosta L, Liotta L, Kranzler A. Game-based cognitive-behavioral therapy individual model (GB-CBT-IM) for child sexual abuse: A preliminary outcome study. Psychological Trauma: Theory, Research, Practice, and Policy. 2014; 6:250-258.

Moradi AR, Taghavi R, Neshat-Doost H, Yule W, Dalgleish T. Memory bias for emotional information in children and adolescents with posttraumatic stress disorder. Journal of Anxiety Disorders. 2000; 14:521-534. [PubMed: 11095544]

Morsette A, Van Den Pol R, Schuldberg D, Swaney G, Stolle D. Cognitive behavioral treatment for trauma symptoms in American Indian youth: Preliminary findings and issues in evidence-based practice and reservation culture. Advances in School Mental Health Promotion. 2012; 5(1):51-62.

Murray LK, Familiar I, Skavenski S, Jere E, Cohen J, Imasiku M, Bolton P. An evaluation of Traumafocused cognitive behavioral therapy for children in Zambia. Child Abuse and Neglect. 2013; 37:1175-1185. [PubMed: 23768939]

Nilsson D, Wadsby M. Symboldrama, a psychotherapeutic method for adolescents with dissociative and PTSD symptoms: A pilot study. Journal of Trauma \& Dissociation. 2010; 11(3):308-321. [PubMed: 20603765] 
Nixon RDV, Sterk J, Pearce A. A randomized trial of cognitive behavior therapy and cognitive therapy for children with posttraumatic stress disorder following single-incident trauma. Journal of Abnormal Child Psychology. 2012; 40:327-337. [PubMed: 21892594]

O'Callaghan P, McMullen J, Shannon C, Rafferty H, Black A. A randomized controlled trial of trauma-focused cognitive behavioral therapy for sexually exploited, war-affected congolese girls. Journal of the American Academy of Child \& Adolescent Psychiatry. 2013; 52(4):359-369. [PubMed: 23582867]

Pfefferbaum B, Newman E, Nelson SD. Mental health interventions for children exposed to disasters and terrorism. Journal of Child and Adolescent Psychopharmacology. 2014; 24(1):24-31. [PubMed: 24494722]

Ready CB, Hayes AM, Yasinski CW, Webb C, Gallop R, Deblinger E, Laurenceau JP. Overgeneralized beliefs, accommodation, and treatment outcome in youth receiving trauma-focused cognitive behavioral therapy for childhood trauma. Behavior Therapy. 2015; 46(5):671-688. [PubMed: 26459847]

Resick PA, Galovski TE, Uhlmansiek MO, Scher CD, Clum GA, Young-Xu Y. A randomized clinical trial to dismantle components of cognitive processing therapy for posttraumatic stress disorder in female victims of interpersonal violence. Journal of Consulting and Clinical Psychology. 2008; 76:243-258. [PubMed: 18377121]

Rodenburg R, Benjamin A, De Roos C, Meijer AM, Stams GJ. Efficacy of EMDR in children: A metaanalysis. Clinical Psychology Review. 2009; 29(7):599-606. [PubMed: 19616353]

Rolfsnes ES, Idsoe T. School-based intervention programs for PTSD symptoms: A review and metaanalysis. Journal of Traumatic Stress. 2011; 24:155-165. [PubMed: 21425191]

Ruf M, Schauer M, Neuner F, Catani C, Schauer E, Elbert T. Narrative exposure therapy for 7- to 16year-olds: A randomized controlled trial with traumatized refugee children. Journal of Traumatic Stress. 2010; 23(4):437-445. [PubMed: 20684019]

Runyon MK, Deblinger E, Schroeder C. Pilot evaluation of outcomes of combined parent-child cognitive-behavioral group therapy for families at risk for child physical abuse. Cognitive and Behavioral Practice. 2009; 16:101-118.

Runyon MK, Deblinger E, Steer RA. Group cognitive behavioral treatment for parents and children atrisk for physical abuse: An initial study. Child \& Family Behavior Therapy. 2010; 32:196-218.

Runyon MK, Ryan E, Kolar R, Deblinger E. An overview of child physical abuse: Developing an integrated parent-child cognitive-behavioral treatment approach. trauma, violence, $\&$ abuse. A Review Journal. 2004; 5:65-85.

Salloum A, Overstreet S. Evaluation of individual and group grief and trauma interventions for children post disaster. Journal of Clinical Child \& Adolescent Psychology. 2008; 37(3):495-507. [PubMed: 18645741]

Salloum A, Overstreet S. Grief and trauma intervention for children after disaster: Exploring coping skills versus trauma narration. Behaviour Research and Therapy. 2012; 50(3):169-179. [PubMed: 22317753]

Salloum A, Robst J, Scheeringa MS, Cohen JA, Wang W, Murphy TK, Storch EA. Step one within stepped care trauma-focused cognitive behavioral therapy for young children: A pilot study. Child Psychiatry \& Human Development. 2014; 45:65-77. [PubMed: 23584728]

Scheeringa MS, Weems CF, Cohen JA, Amaya-Jackson L, Guthrie D. Trauma-focused cognitive behavioral therapy for posttraumatic stress disorder in three through six year-old children: A randomized clinical trial. Journal of Child Psychology and Psychiatry. 2011; 52:853-860. [PubMed: 21155776]

Schoenwald SK. It's a bird, it's a plane, it's ... fidelity measurement in the real world. Clinical Psychology: Science and Practice. 2011; 18(2):142-147. [PubMed: 21691439]

Schottelkorb AA, Doumas DM, Garcia R. Treatment for childhood refugee trauma: A randomized, controlled trial. International Journal of Play Therapy. 2012; 21(2):57-73.

Shirk SR, DePrince AP, Crisostomo PS, Labus J. Cognitive behavioral therapy for depressed adolescents exposed to interpersonal trauma: An initial effectiveness trial. Psychotherapy. 2014; 51(1):167-179. [PubMed: 24377410] 
Silverman WK, Hinshaw SP. The second special issue on evidence-based psychosocial treatments for children and adolescents: A 10-year update. Journal of Clinical Child \& Adolescent Psychology. 2008; 37(1):1-7.

Silverman WK, Ortiz CD, Viswesvaran C, Burns BJ, Kolko DJ, Putnam FW, Amaya-Jackson L. Evidence-based psychosocial treatments for children and adolescents exposed to traumatic events. Journal of Clinical Child \& Adolescent Psychology. 2008; 37(1):156-183. [PubMed: 18444057]

Southam-Gerow MA, McLeod BD. Advances in applying treatment integrity research for dissemination and implementation science: Introduction to special issue. Clinical Psychology: Science and Practice. 2013; 20:1-13. doi: cpsp.12019/cpsp.12019. [PubMed: 23970819]

Southam-Gerow MA, Prinstein MJ. Evidence base updates: The evolution of the evaluation of psychological treatments for children and adolescents. Journal of Clinical Child \& Adolescent Psychology. 2014; 43(1):1-6. [PubMed: 24294989]

Spence SH, Donovan C, Brechman-Toussaint M. The treatment of childhood social phobia: The effectiveness of a social skills training-based, cognitive-behavioural intervention, with and without parental involvement. Journal of Child Psychology and Psychiatry. 2000; 41(6):713-726. [PubMed: 11039684]

Squires JE, Suh KN, Linklater S, Bruce N, Gartke K, Graham ID, Grimshaw JM. Improving physician hand hygiene compliance using behavioural theories: A study protocol. Implementation Science. 2013; 8(16):1-9. [PubMed: 23279972]

Staples JK, Atti JAA, Gordon JS. Mind-body skills groups for posttraumatic stress disorder and depression symptoms in Palestinian children and adolescents in Gaza. International Journal of Stress Management. 2011; 18:246-262.

Swenson CC, Schaeffer CM, Henggeler SW, Faldowski R, Mayhew AM. Multisystemic therapy for child abuse and neglect: A randomized effectiveness trial. Journal of Family Psychology. 2010; 24:497-507. [PubMed: 20731496]

Tol WA, Komproe IH, Jordans MJ, Ndayisaba A, Ntamutumba P, Sipsma H, De Jong JT. School-based mental health intervention for children in war-affected Burundi: A cluster randomized trial. BMC Medicine. 2014; 12(56):1-12.

Tol WA, Komproe IH, Susanty D, Jordans MJ, Macy RD, De Jong JT. School-based mental health intervention for children affected by political violence in Indonesia: A cluster randomized trial. The Journal of the American Medical Association. 2008; 300(6):655-662. [PubMed: 18698064]

Trask EV, Walsh K, DiLillo D. Treatment effects for common outcomes of child sexual abuse: A current meta-analysis. Aggression and Violent Behavior. 2011; 16:6-19. [PubMed: 21603060]

Trickett PK, Noll JG, Putnam FW. The impact of sexual abuse on female development: Lessons from a multigenerational, longitudinal research study. Development and Psychopathology. 2011; 23:453-476. [PubMed: 23786689]

Trocmé, N., Wolfe, D. Child maltreatment in Canada: Selected results from the Canadian incidence study of reported child abuse and neglect. Ottawa, Ontario: Minister of Public Works and Government Services Canada; 2001.

U.S. Census Bureau. Licensed drivers and number in accidents by age: 2009. Washington, DC: Author; 2012. Retrieved from http://www.census.gov/compendia/statab/cats/transportation/ motor_vehicle_accidents_and_fatalities.html

Van Der Oord S, Lucassen S, Van Emmerik AAP, Emmelkamp PMG. Treatment of post-traumatic stress disorder in children using Cognitive behavioural writing therapy. Clinical Psychology \& Psychotherapy. 2010; 17(3):240-249. [PubMed: 20013756]

Wamser-Nanney R, Scheeringa MS, Weems CF. Early treatment response in children and adolescents receiving CBT for trauma. Journal of Pediatric Psychology. 2014 Advance online publication.

Weems CF, Scheeringa MS. Maternal depression and treatment gains following a cognitive behavioral intervention for post-traumatic stress in preschool children. Journal of Anxiety Disorders. 2013; 27:140-146. [PubMed: 23376601]

Weisz, JR. Psychotherapy for children and adolescents: Evidence-based treatments and case examples. Cambridge, England: Cambridge University Press; 2004.

Weisz JR, Chorpita BF, Palinkas LA, Schoenwald SK, Miranda J, Bearman SK. the Research Network on Youth Mental Health. Testing standard and modular designs for psychotherapy treating 
depression, anxiety, and conduct problems in youth: a randomized effectiveness trial. Archives of General Psychiatry. 2012; 69:274-282. [PubMed: 22065252]

Weisz, JR., Southam-Gerow, M., Gordis, EB., Connor-Smith, J. Primary and secondary control enhancement training for youth depression: Applying the deployment-focused model of treatment development and testing. In: Kazdin, AE., Weisz, JR., editors. Evidence-based psychotherapies for children and adolescents. New York, NY: Guilford Press; 2003. p. 165-183.

Wethington HR, Hahn RA, Fuqua-Whitley DS, Sipe TA, Crosby AE, Johnson RL, Task Force on Community Preventive Services. The effectiveness of interventions to reduce psychological harm from traumatic events among children and adolescents: A systematic review. American Journal of Prevention Medicine. 2008; 35(3):287-313.

Yasinski C, Hayes A, Ready B, Cummings J, Berman I, McCauley T, Deblinger E. In-session caregiver behavior predicts symptom change in youth receiving Trauma-focused Cognitive Behavioral Therapy (TF-CBT). Journal of Consulting and Clinical Psychology. 2016

Zatzick DF, Koepsell T, Rivara FP. Using target population specification, effect size, and reach to estimate and compare the population impact of two PTSD preventive interventions. Psychiatry: Interpersonal and Biological Processes. 2009; 72(4):346-359. 
Step 1: Generated search terms related to: (a) trauma exposure, (b) treatment.

Step 2: Replaced author-generated terms with synonyms generated from Psychlnfo and PubMed thesauri.

Step 3: Entered terms into search engines to ensure all cross-category combinations ([a] trauma exposure, [b] treatment) were returned.

Step 4: Set search parameters to: Publication date (Jan. 12007 - May 1 2014); Species

(Human), Age (0-18 years); Publication type (peer-reviewed journal)

First Round Inclusion

Step 1: Scanned titles, abstracts, and method sections to select research articles that satisfied the following initial inclusion criteria:

- Participants with potential trauma exposure

- Measures of psychological outcomes

Step 2: Examined relevant review articles returned by the search for additional research article references.

$\mathrm{n}=188$ studies

\section{Second Round Inclusion}

Full-text articles were read to satisfy a stricter set of exclusionary criteria that included:

- Study did not focus on treating trauma exposure and mental health sequelae $(n=50)$

- Single case or multiple baseline studies $(n=7)$

- Methods did not include individual-level screening for trauma exposure $(n=12)$;

- elevated mental health symptoms $(n=32)$; or both $(n=11)$

- Participants were older than 0-18 years or outcomes were not examined separately for older participants $(n=13)$

- Other reasons (e.g., duplicate study, only qualitative outcomes, not in English, included in Silverman et al.. 2008. etc.). ( $n=27)$

\begin{tabular}{|c|c|}
\hline $\mathrm{n}=37$ studies & \\
\hline \multicolumn{2}{|c|}{ Studies by Treatment Type } \\
\hline $\begin{array}{l}\text { - Individual CBT with Parent Involvement } \\
\text { (11) } \\
\text { - Individual CBT }(8)^{\star \wedge} \\
\text { - Group CBT }(6)^{\star} \\
\text { - Eye Movement Desensitization and } \\
\text { Reprocessing (3) } \\
\text { - Individual Integrated Therapy for Complex } \\
\text { Trauma (3) }\end{array}$ & $\begin{array}{l}\text { - Group CBT with Parent Involvement (2) } \\
\text { - Group Creative Expressive + CBT (2) } \\
\text { - Group Mind-Body Skills (2) } \\
\text { - Individual Psychoanalysis (1) } \\
\text { - Individual Client-Centered Play Therapy (1) } \\
\text { - Individual Mind-Body Skills (1)^ }\end{array}$ \\
\hline
\end{tabular}

FIGURE 1.

Search strategies. 
TABLE 1

Description of Treatment Reviews for Children and Adolescents Exposed to Traumatic Events

\begin{tabular}{|c|c|c|}
\hline Study & $\begin{array}{l}\text { Type of } \\
\text { Review }\end{array}$ & $\begin{array}{l}\text { Age; Years Covered, Study } N \text {; Treatment Type; } \\
\text { Criteria } \\
\text { (i.e., Trial Types, Trauma Type, Use of Measures, etc.) }\end{array}$ \\
\hline $\begin{array}{l}\text { Cary \& } \\
\text { McMillen, } 2012\end{array}$ & $\begin{array}{l}\text { Systematic } \\
\text { Review; } \\
\text { Meta- } \\
\text { Analysis }\end{array}$ & $\begin{array}{l}\text { Age: }<18 ; 1990-2011 ; N=10 \\
\text { Tx: TF-CBT or similar interventions (e.g. CBITS, CBT, } \\
\text { \& RAPP); } \\
\text { Crx: RCTs, used at least } 4 \text { of the major components of } \\
\text { TF-CBT; participants had survived at least one } \\
\text { traumatic event, assessed syx of PTSD; }\end{array}$ \\
\hline $\begin{array}{l}\text { De Arellano et al., } \\
2014\end{array}$ & Qualitative & $\begin{array}{l}\text { Age: Not reported; } 1995-2013 ; N=16 \\
\text { Tx: TF-CBT; } \\
\text { Crx: RCTs, quasi-experimental; open trials; meta- } \\
\text { analyses \& systematic review articles; }\end{array}$ \\
\hline $\begin{array}{l}\text { Dorsey, Briggs, \& } \\
\text { Woods, } 2011\end{array}$ & Qualitative & $\begin{array}{l}\text { Age: Not reported; Years covered not reported; } N \text { not } \\
\text { reported } \\
\text { Tx: TF-CBT, CBITS, TGCT, TST, CPC-CBT, SPARCS, } \\
\text { TFC (aka MMTT), RRFT, TARGET-A; } \\
\text { Crx: RCTs, quasi-experimental, open trials, field trials, } \\
\text { single-case cross-setting design; }\end{array}$ \\
\hline $\begin{array}{l}\text { Dowd \& } \\
\text { McGuire, } 2011\end{array}$ & Qualitative & $\begin{array}{l}\text { Age: } 3-18 \text {; Years covered not reported; } N \text { not reported } \\
\text { Tx: Interventions w/empirical support (individual \& } \\
\text { group CBT, TF-CBT, Anxiety Management Training, } \\
\text { EMDR, behavioral, CISD, psychodynamic, Parental/ } \\
\text { Family involvement, emerging therapies [e.g., Child- } \\
\text { Parent Psychotherapy; Kids Club]); } \\
\text { Crx: Trauma exp, children w/PTSD syx; }\end{array}$ \\
\hline
\end{tabular}

Forman-Hoffman Qualitative Age: $<18 ; 1990$ onward; $N=25$

et al., $2013 \quad$ Tx: TF-CBT, CFTSI, mixed, early psychological intervention, pharmacotherapies

Crx: Trauma exp, psychotherapy, pharmacotherapy;

Fraser et al., 2013 Systematic Age: $<14 ; 1990-2012 ; N=17$

Review Tx: Pharmalogical and psychosocial interventions (e.g., parent-mediated approaches or TF treatments); Crx: RCTs (6 TF treatments, 10 parenting interventions), NCT (1 TF treatment), U.S. \& international;

Gillies, Taylor, $\quad$ Systematic $\quad$ Age: $3-18$; Years covered not reported; $N=14$

Gray, O'Brien, \& Review; Tx: All psychological therapies including CBT,

D'Abrew, 2012 Meta- exposure-based, psychodynamic, narrative, supportive

Analysis counseling, family-based, \& EMDR;

Crx: RCTs; children/adolescents exposed to traumatic event or diagnosed w/PTSD;

Harvey \& Taylor, $\quad$ Meta- $\quad$ Age: $<18$; Years covered not reported; $N=39$

$2010 \quad$ Analysis

Tx: CBT or insight-oriented;

Crx: Results based on empirical measures, studied tx outcomes for CSA with children/adolescents, at least $50 \%$ sample experienced CSA, no single case studies; enough data to calculate ES, independent data set;

Findings

PTS: moderate ES $(g=.671)$; depr and bx

problems: small

ES $(g=.378 ; .247)$; ES similar for

"branded" TF-CBT

and similar interventions; PTS effect

maintained at $1-\mathrm{yr}$

High level of evidence for TF-CBT for PTS: compared to

active control, TF-CBT groups showed

consistent

decreases in PTSD syx, maintained at 12 -

month FU;

moderate/mixed evidence for TF-CBT

effectiveness on

bx problems \& depr syx

PTSD syx improved, retained over time

Strong evidence for TF-CBT w/range of ages and traumas;

EMDR well-supported; anx management

and behavioral

tx alone not shown to be effective (but typically included

in TF-CBT); group CBT has some support especially in

response to community-wide events; little evidence for

Psychodynamic, Play, Art Therapy, or

CISD; CISD may

have negative effects

Most studies comparing tx with WLC show improvement;

studies comparing tx with active controls

showed no

improvement (with one exception); schoolbased CBT

appeared promising; little evidence on effectiveness

related to individual child differences

Strength of evidence low for all but one of the interventions

Across all therapies, improvement for syx of PTSD, anx,

and depr within 1 mo of completing therapy compared to

a control group; CBT had best evidence of effectiveness

CBT approaches: biggest trx effect; large ES for global

outcomes ( $g=1.37$ ), PTSD/trauma ( $g=$

$1.12)$; moderate

ES for int $(g=0.74)$, ext syx $(g=0.52)$; effects 


\begin{tabular}{lll}
\hline Type of & $\begin{array}{l}\text { Age; Years Covered, Study } N \text {; Treatment Type; } \\
\text { Review } \\
\text { (i.e., Trial Types, Trauma Type, Use of Measures, etc.) }\end{array}$ \\
\hline
\end{tabular}

Leenarts, Diehle,

Doreleijers,

Jansma, \&

Lindauer, 2013

Macdonald et al., 2012

Pfefferbaum, Newman, \& Nelson, 2014

$\begin{array}{lc}\begin{array}{l}\text { Rodenberg, } \\ \text { Benjamin, de } \\ \text { Roos, Meijer, \& } \\ \text { Stams, 2009 }\end{array} & \begin{array}{c}\text { Meta- } \\ \text { Analysis }\end{array} \\ \begin{array}{l}\text { Rolfsnes \& Idsoe, } \\ 2011\end{array} & \begin{array}{c}\text { Meta- } \\ \text { Analysis }\end{array} \\ & \\ \text { Trask et al., 2011 } & \begin{array}{c}\text { Meta- } \\ \text { Analysis }\end{array}\end{array}$

Wethington et al., 2008

\section{Systematic}

Review

MetaAnalysis

Review;

Meta-

Analysis
Age: 6-17; 2000-2012; $N=33$

Tx: CBT techniques vs. WLC, delayed treatment, TAU, other active treatments, or no treatments; Crx: RCTs or non-randomized trials, exp to CM, assess PTSD or PTSD syx associated with CM;

Age: < 18; Up to 2011; $N=10$

Tx: CBT vs. WLC or TAU;

Crx: Randomized or quasi-randomized controlled trials of CBT, children/adolescents who experienced CSA;

Qualitative Age: Not reported; Search conducted January 2013; N $=85$

Tx: Interventions used w/children exposed to disasters and terrorism (preparedness interventions, psychological first aid, psychological debriefing, psychoeducation, CBT techniques, exp and TN, EMDR, and TG);

Crx: Intervention studies w/outcomes, only noninterpersonal trauma;

Age: $<18 ; 2002-2008 ; N=7$

Tx: EMDR vs. established trauma treatments or TAU or WLC;

Crx: children/adolescents treated for post-traumatic stress reactions, RCT; pre- and post-treatment trauma scores

Age: Not reported; Search conducted May 2010; $N=19$ Tx: School-based intervention targeting PTSD syx (CBT, play/art, EMDR, mind-body skills);

Crx: Randomized or quasi-experimental w/at least $1 \mathrm{WLC}$ or alternative intervention control; school setting; trauma exp; standardized PTSD instruments;

Tx: negative outcomes of CSA (PTSD syx, ext and int problems);

Crx: Single group and between group designs;

Systematic Age: $\leq 21$; Up to 2007; $N=11$
Tx: Individual or group CBT, play, art, psychodynamic, and pharmacologic therapy; psychological debriefing);

Crx: trauma exp \& at least one mental health syx, included only primary studies of high-income countries \& a control group;
Findings

maintained at $\mathrm{FU}(>6 \mathrm{mo})$ for some

outcomes

Scarcity of rigorous studies, diversity of interventions, \&

mixed results of evaluations; this study contained 54

intervention descriptions and 12 tx outcome studies with

moderate ES

CBT effective in treating childhood PTSD; CBT

interventions improved scores on Total Problems, Int,

and Ext scales of CBCL relative to active control; some

evidence CBT better addresses int vs. ext syx

TF-CBT: best-supported treatment for children following

$\mathrm{CM}$; CBITS is the best treatment option for children who

can be treated in groups in their school settings

CBT may have positive impact, but results not statistically

significant;

Moderate effects in reducing PTSD, depr, \& anx syx

Preparedness interventions, CBT in multiple forms, \&

traumatic grief interventions appear

beneficial; exp and

narrative interventions and EMDR have positive

outcomes but unclear if superior to other trx

EMDR is efficacious in treating PTSD sx;

EMDR shows

incremental efficacy compared to

established trx, WLC,

and TAU

Medium-large ES $(d=0.68)$ for PTSD syx

Individual and group treatments equally

effective for

children exposed to CSA; group may be the most

practical treatment modality

Community Guide Rules: CBT (individual and group) had

the best evidence; insufficient evidence for

all other

interventions

Note anx $=$ anxiety $; \mathrm{bx}=$ behavior $\mathrm{CBCL}=$ Child Behavior Checklist $=$ CBITS: Cognitive Behavioral Intervention for Trauma in Schools; $\mathrm{CBT}=$ Cognitive Behavioral Therapy; CFTSI = Child and Family Traumatic Stress Intervention; CISD = Critical Incident Stress Debriefing; CM = child maltreatment; $\mathrm{CPC}-\mathrm{CBT}=$ Combined Parent-Child Cognitive Behavioral Approach for Children and Families; $\mathrm{crx}=\mathrm{criteria}$; $\mathrm{CSA}=\mathrm{Childhood}$ Sexual Assault; depr = depression; EMDR = Eye Movement Desensitization and Reprocessing; ES = effect size; exp = exposure; ext = externalizing; FU = follow-up; int $=$ internalizing; MMTT $=$ Multimodality Trauma Treatment $;$ mo $=$ month $;$ NCT $=$ nonrandomized controlled 
trial PTSD $=$ Post-Traumatic Stress Disorder; RAPP $=$ Recovering from Abuse Program $; \mathrm{RCT}=$ Randomized controlled trial $;$ RRFT $=$ Risk Reduction through Family Therapy; SPARCS = Structures Psychotherapy for Adolescents Responding to Chronic Stress; syx = symptoms;

TARGET-A = Trauma Adaptive Recovery Group Education and Therapy for Adolescents and Pre-Adolescents; TAU = Treatment as Usual; TF = trauma-focused; TFC $=$ Treatment Fidelity Checklist TF-CBT $=$ Trauma-Focused Cognitive Behavioral Therapy TG $=$ traumatic grief; TGCT $=$

Trauma and Grief Component Therapy; TN = trauma narrative; TST $=$ Trauma Systems Therapy; $\mathrm{tx}=$ treatment WLC $=$ waitlist $\operatorname{control} ; \mathrm{yr}=$ year 


\section{TABLE 2}

\section{JCCAP Evidence Base Updates Evidence-Based Treatment Evaluation Criteria}

\section{Methods criteria}

M.1. Group design: Study involved a randomized controlled design

M.2. Independent variable defined: Treatment manuals or logical equivalent were used for the treatment

M.3. Population clarified: Conducted with a population, treated for specified problems, for whom inclusion criteria have been clearly delineated

M.4. Outcomes assessed: Reliable and valid outcome assessment measures gauging the problems targeted (at a minimum) were used

M.5. Analysis adequacy: Appropriate data analyses were used and sample size was sufficient to detect expected effects

Level 1: Well-Established Treatments

Evidence criteria

1.1 Efficacy demonstrated for the treatment by showing the treatment to be either:

1.1.a. Statistically significantly superior to pill or psychological placebo or to another active treatment

OR

1.1.b. Equivalent (or not significantly different) to an already well-established treatment in experiments

AND

1.1c. In at least two (2) independent research settings and by two (2) independent investigatory teams demonstrating efficacy AND

1.2. All five (5) of the Methods Criteria

Level 2: Probably Efficacious Treatments

Evidence criteria

2.1 There must be at least two good experiments showing the treatment is superior (statistically significantly) to a waitlist control group

OR

2.2 One (or more) experiments meeting the Well-Established Treatment level except for criterion 1.1c (i.e., Level 2 treatments will not involve independent

investigatory teams)

AND

2.3 All five (5) of the Methods Criteria

Level 3: Possibly Efficacious Treatments

Evidence criteria

3.1 At least one good randomized controlled trial showing the treatment to be superior to a waitlist or no-treatment control group

AND

3.2 All five (5) of the Methods Criteria

OR

3.3 Two or more clinical studies showing the treatment to be efficacious, with two or more meeting the last four (of five) Methods Criteria, but none being

randomized controlled trials

Level 4: Experimental Treatments

Evidence criteria

4.1. Not yet tested in a randomized controlled trial

OR

4.2. Tested in one or more clinical studies but not sufficient to meet Level 3 criteria

Level 5: Treatments of Questionable Efficacy

J Clin Child Adolesc Psychol. Author manuscript; available in PMC 2017 May 01. 
5.1. Tested in good group-design experiments and found to be inferior to other treatment group and/or wait-list control group, that is, only evidence available

from experimental studies suggests the treatment produces no beneficial effect

Note. Adapted from Silverman and Hinshaw (2008) and Division 12 Task Force on Psychological Interventions' reports (Chambless et al., 1996, 1998), from Chambless and Hollon (1998), and from Chambless and Ollendick (2001). Chambless and Hollon (1998) described criteria for methodology. 


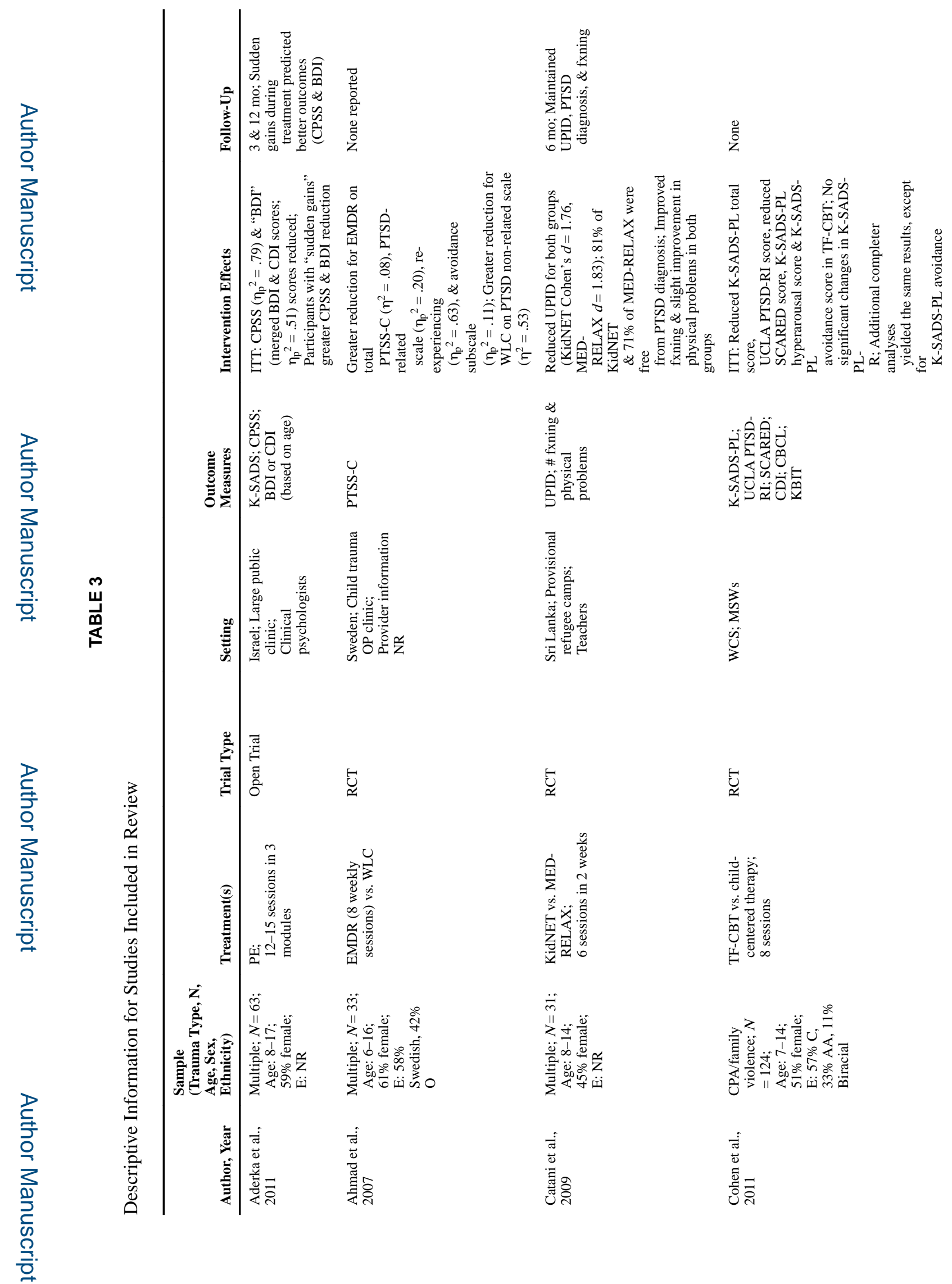

J Clin Child Adolesc Psychol. Author manuscript; available in PMC 2017 May 01. 


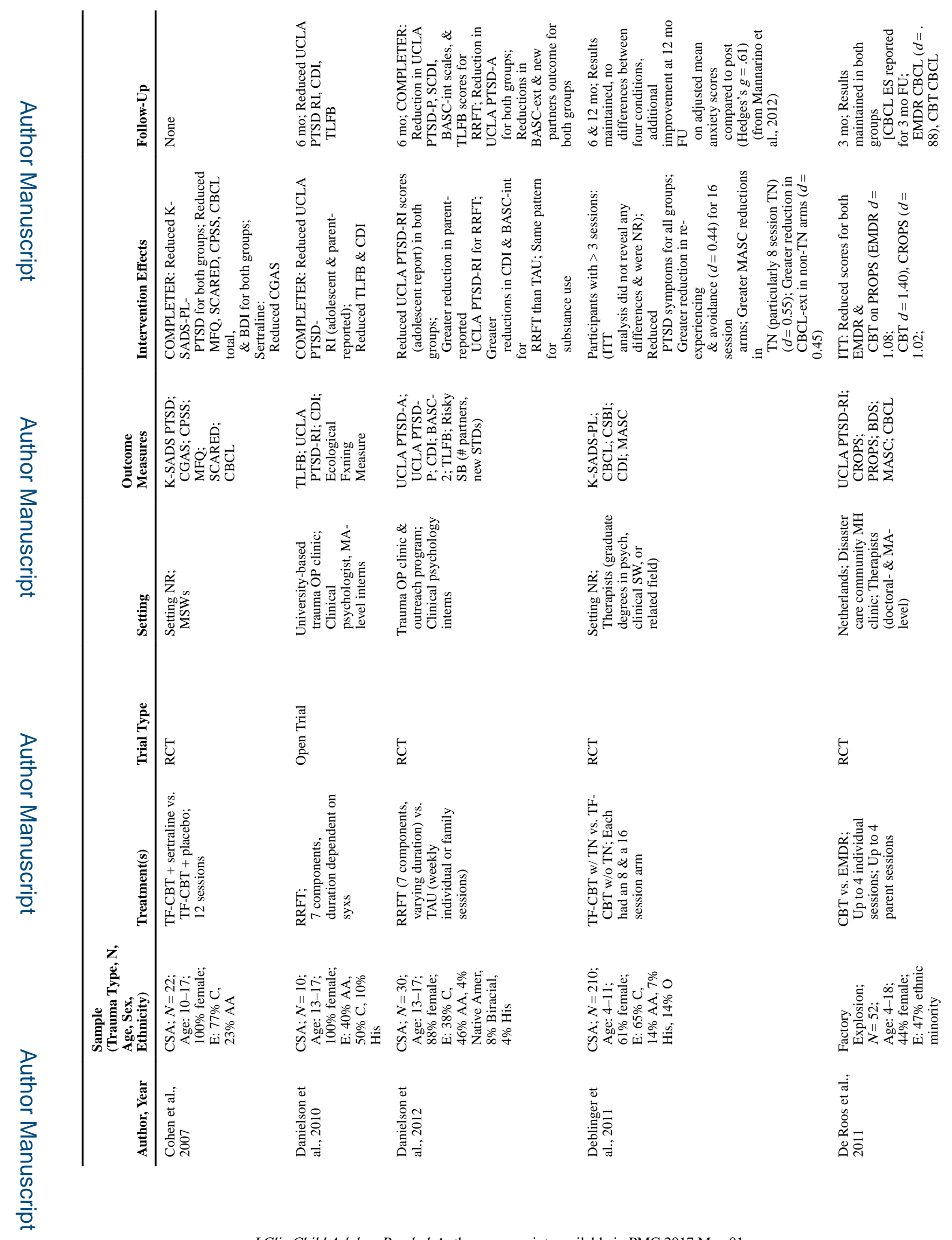

J Clin Child Adolesc Psychol. Author manuscript; available in PMC 2017 May 01. 
Dorsey et al.

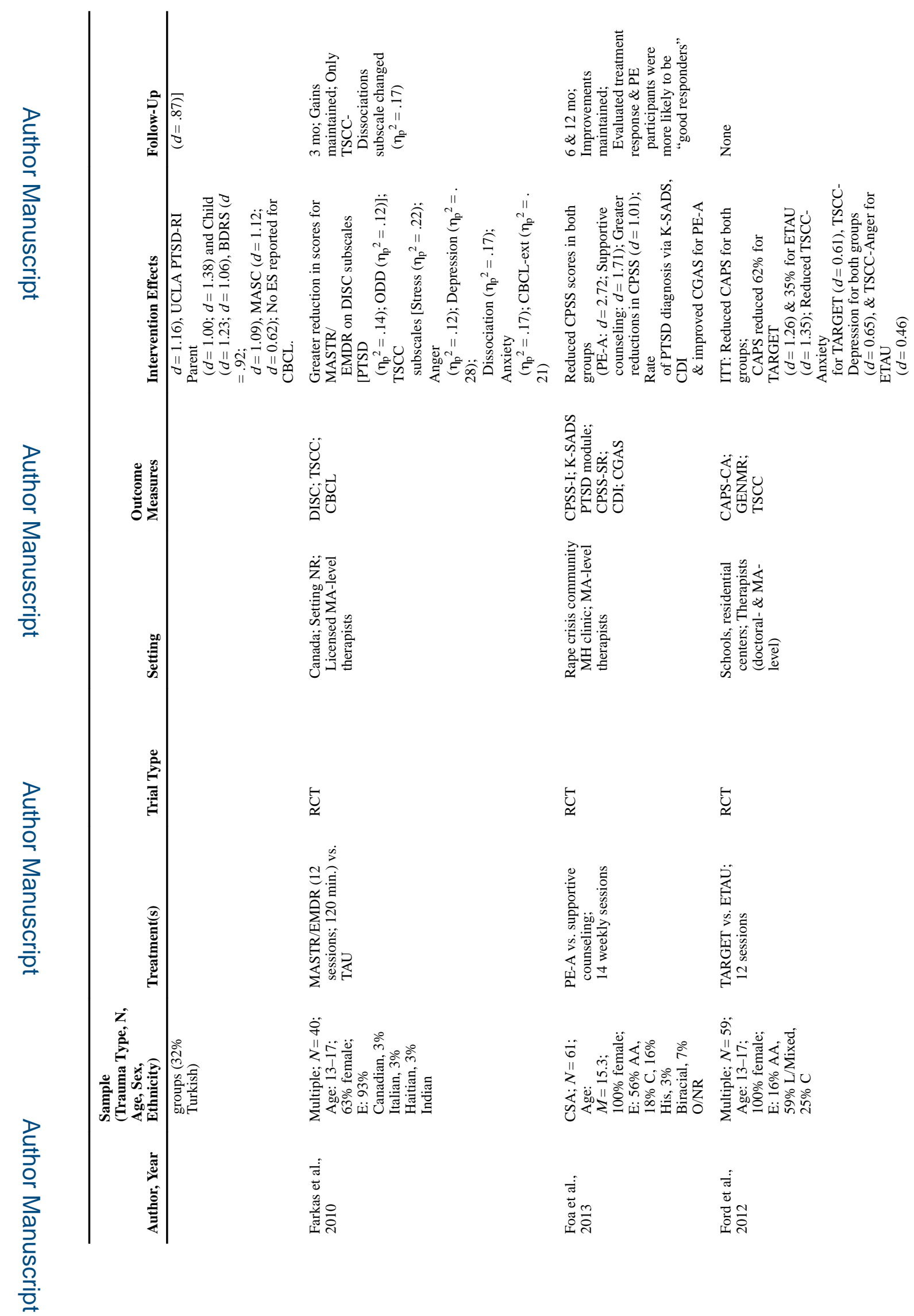

J Clin Child Adolesc Psychol. Author manuscript; available in PMC 2017 May 01. 


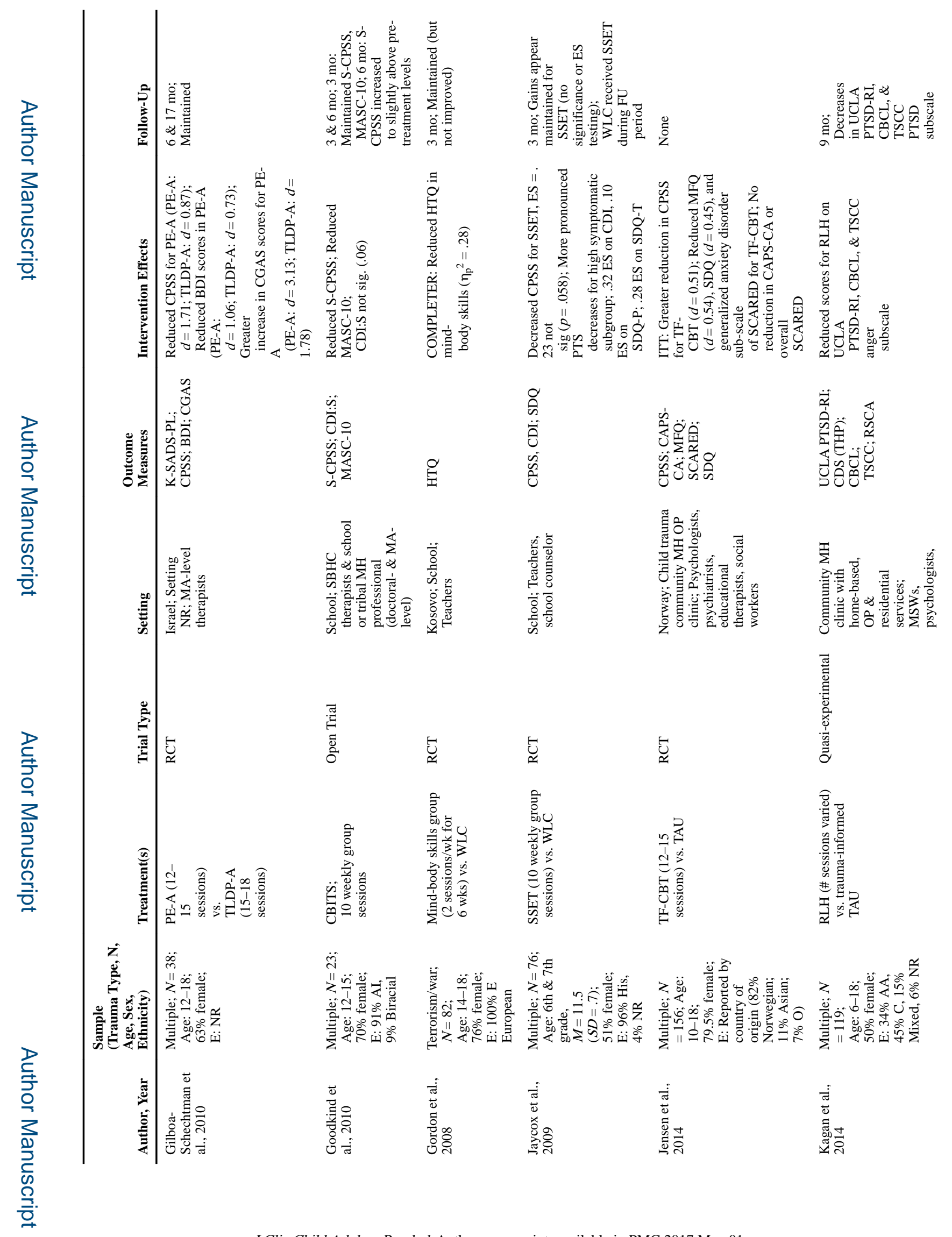

J Clin Child Adolesc Psychol. Author manuscript; available in PMC 2017 May 01. 


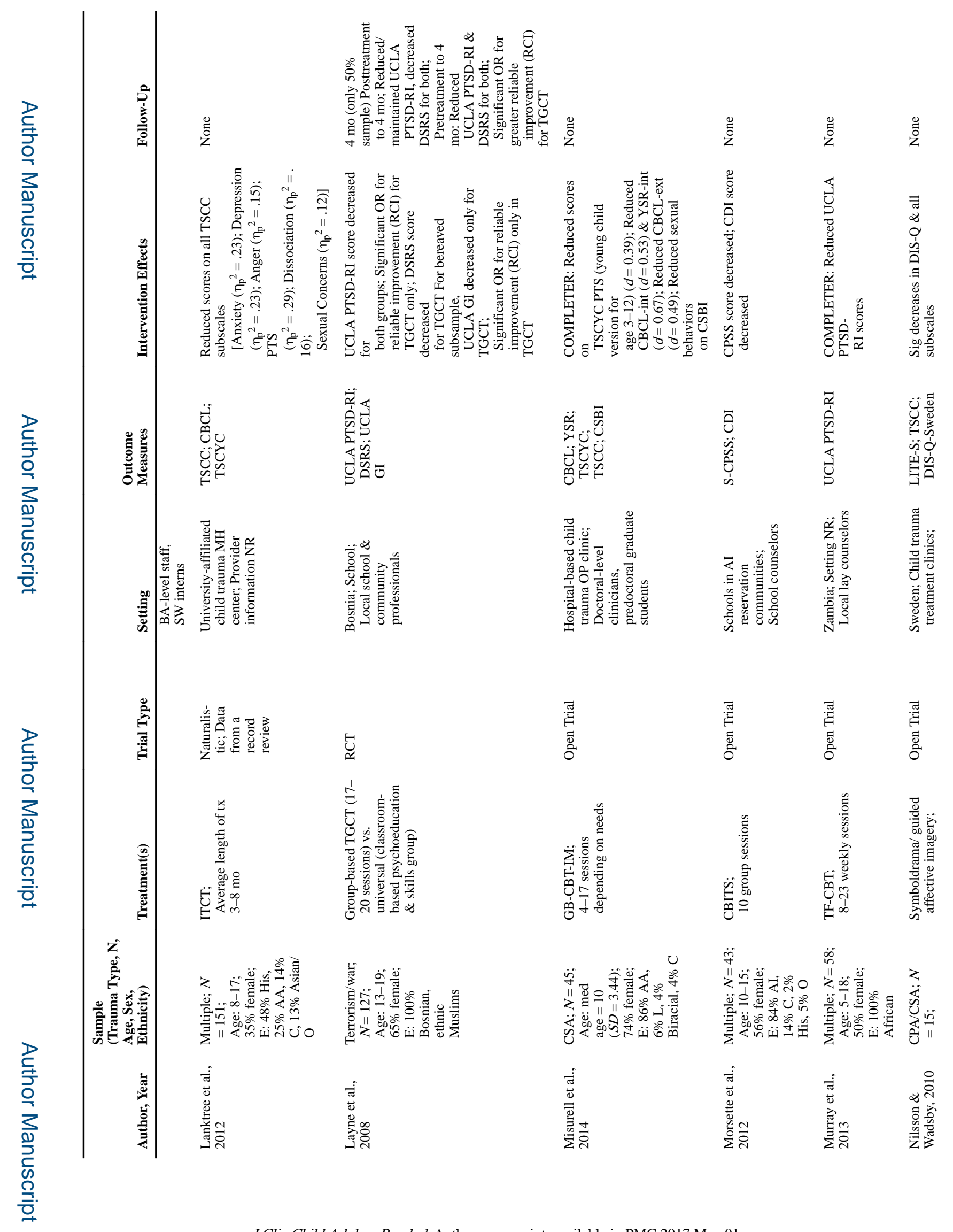

J Clin Child Adolesc Psychol. Author manuscript; available in PMC 2017 May 01. 


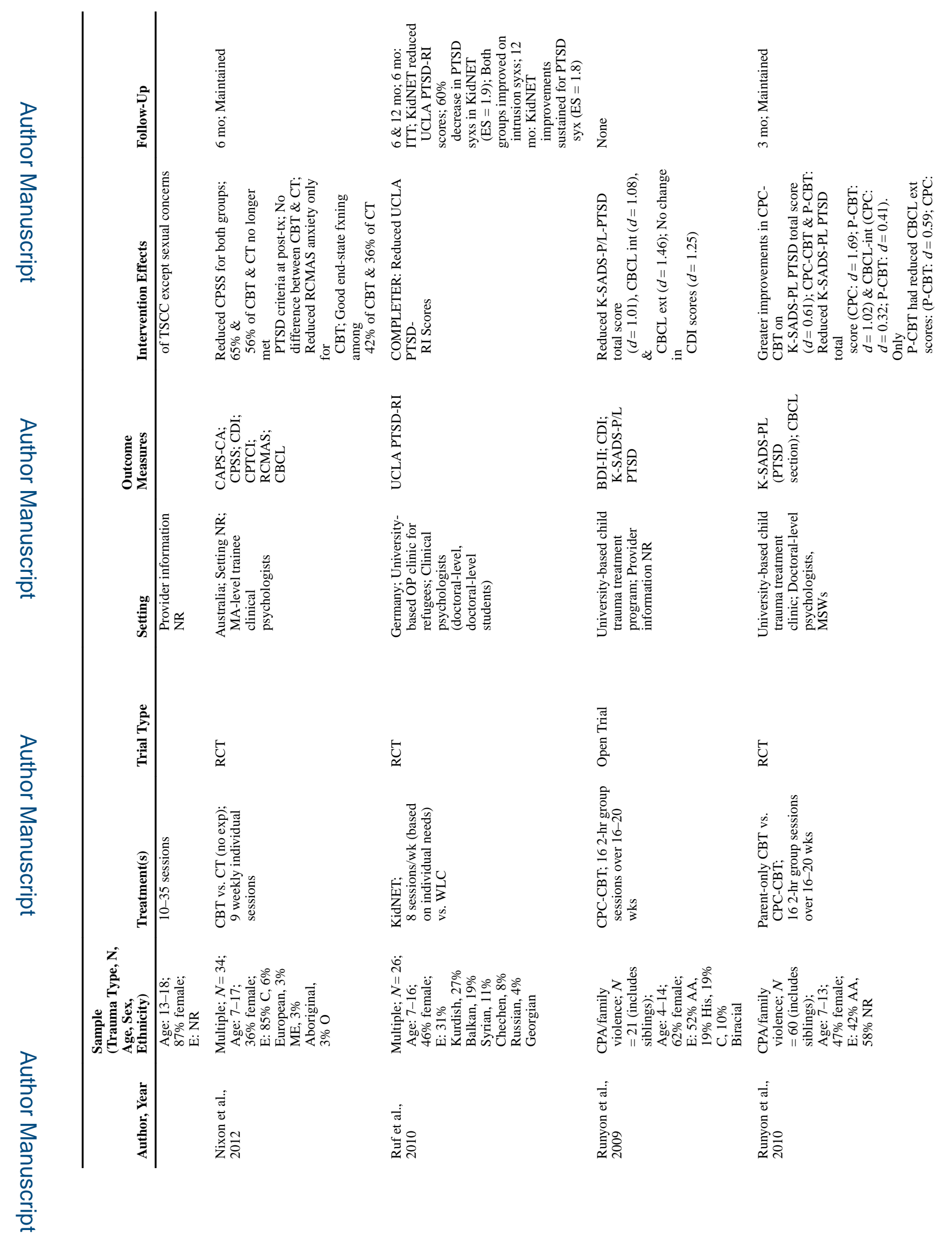

J Clin Child Adolesc Psychol. Author manuscript; available in PMC 2017 May 01. 


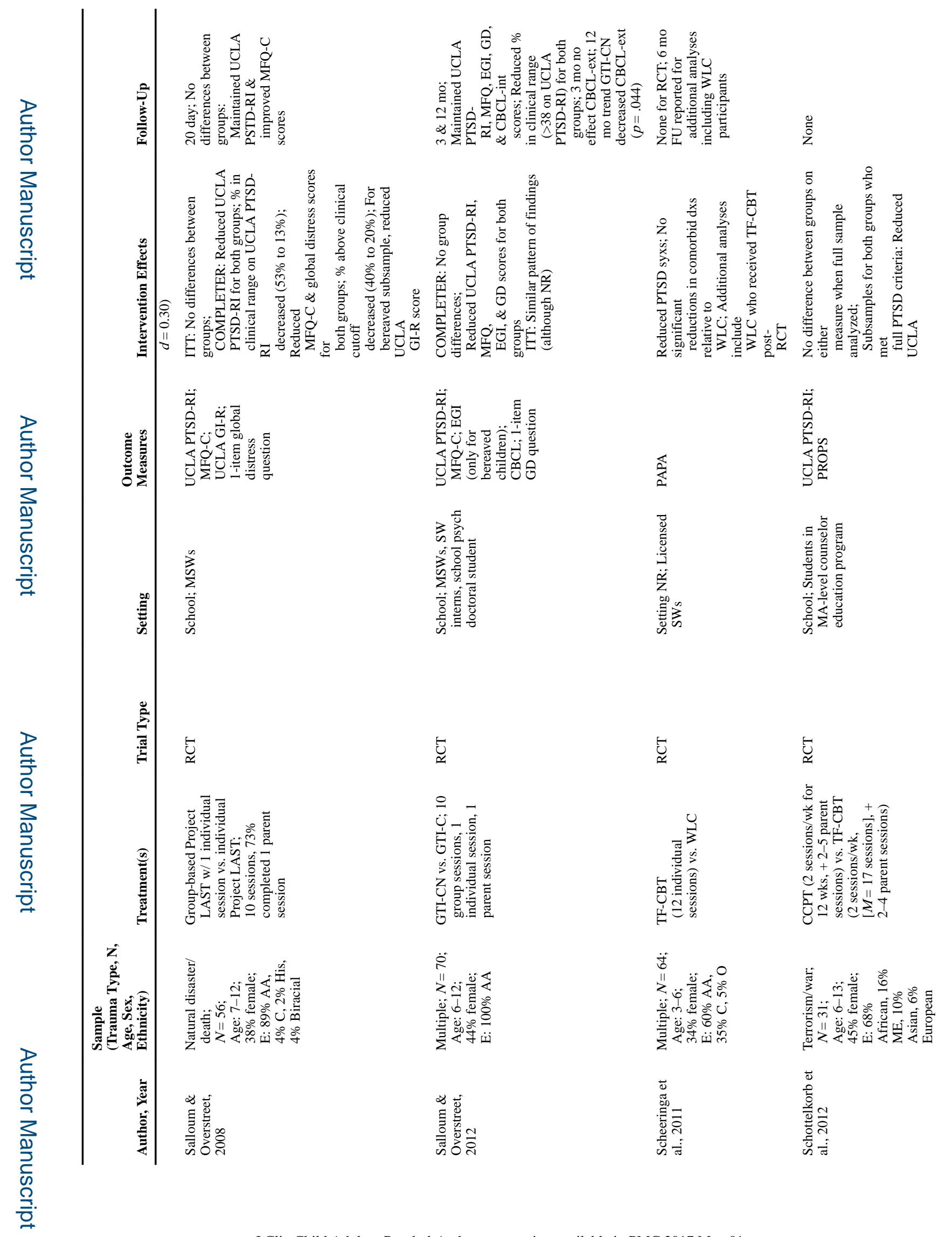

J Clin Child Adolesc Psychol. Author manuscript; available in PMC 2017 May 01. 


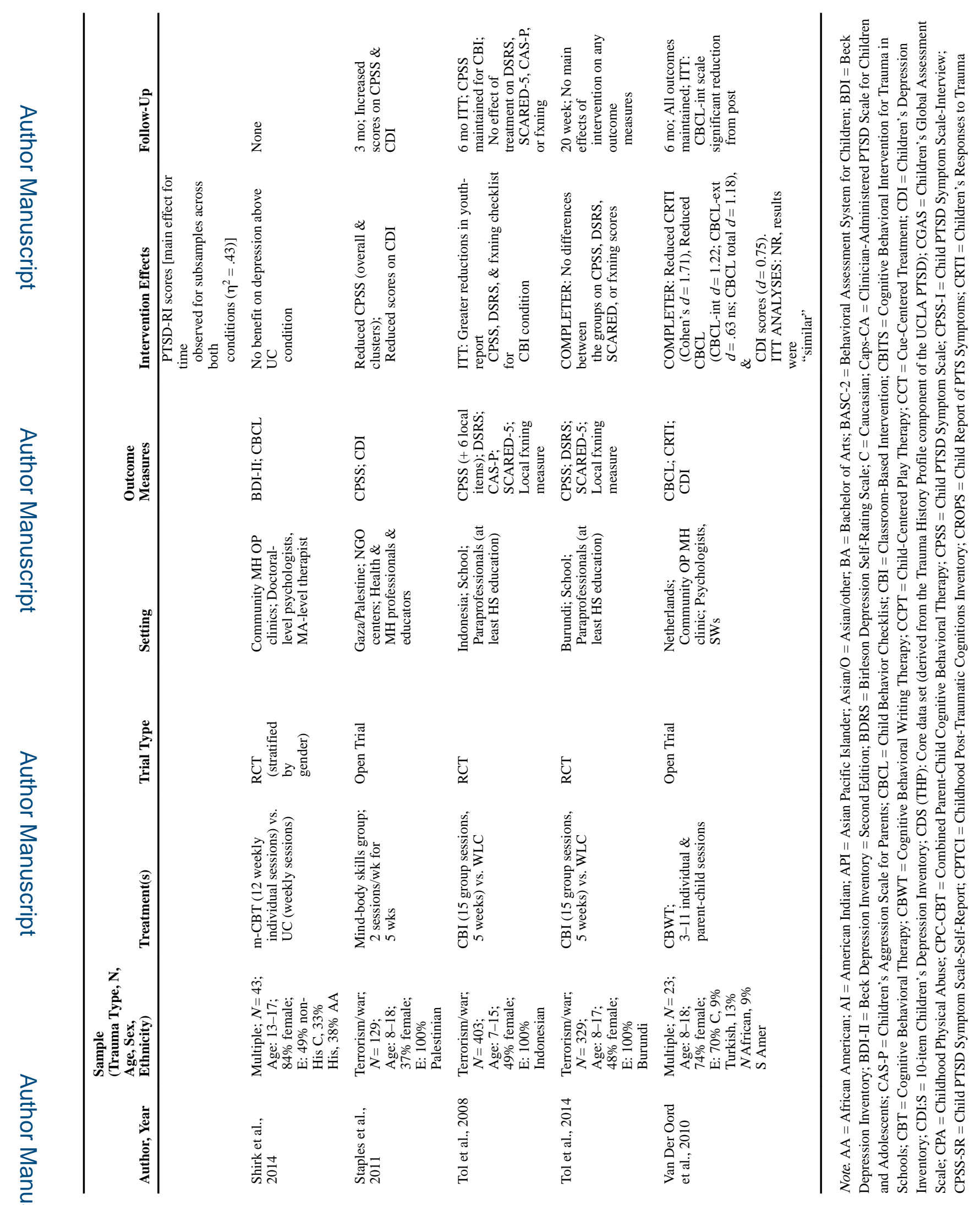

J Clin Child Adolesc Psychol. Author manuscript; available in PMC 2017 May 01. 


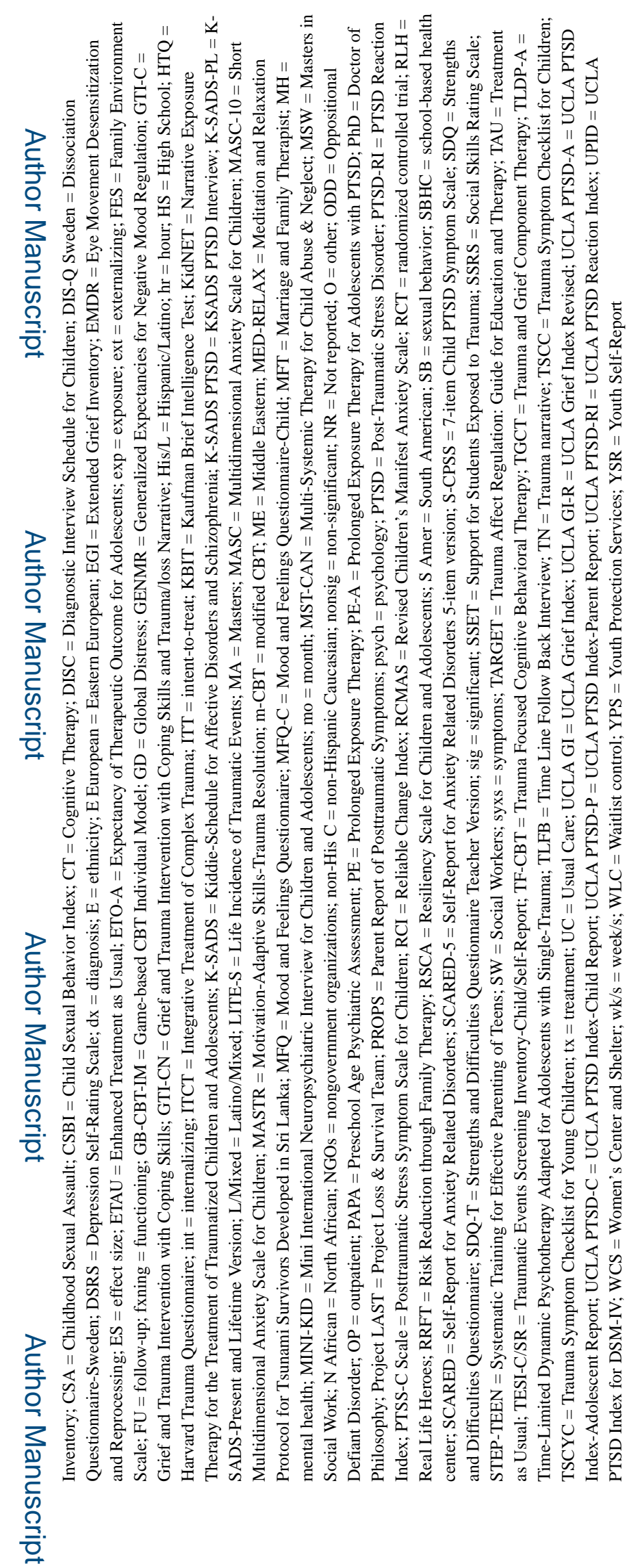

J Clin Child Adolesc Psychol. Author manuscript; available in PMC 2017 May 01. 
TABLE 4

Evidence Base Update for Treatment of Child Trauma Exposure: Summary Table

\begin{tabular}{|c|c|c|c|c|}
\hline Level 1: Well-Established & $\begin{array}{l}\text { Level 2: Probably } \\
\text { Efficacious }\end{array}$ & Level 3: Possibly Efficacious & Level 4: Experimental & $\begin{array}{l}\text { Level 5: Questionable } \\
\text { Efficacy }\end{array}$ \\
\hline $\begin{array}{l}\text { Individual CBT with Parent } \\
\text { Involvement }\end{array}$ & $\begin{array}{l}\text { Group CBT with } \\
\text { Parent } \\
\text { Involvement }\end{array}$ & $\begin{array}{l}\text { Individual Integrated Therapy } \\
\text { for } \\
\text { Complex Trauma }\end{array}$ & $\begin{array}{l}\text { Individual Client-Centered } \\
\text { Play Therapy }\end{array}$ & $\begin{array}{l}\text { Group Creative } \\
\text { Expressive }+ \text { CBT }\end{array}$ \\
\hline Individual CBT & $\begin{array}{l}\text { Eye Movement } \\
\text { Desensitization } \\
\text { and Reprocessing }\end{array}$ & Group Mind-Body Skills & $\begin{array}{l}\text { Individual Mind-Body } \\
\text { Skills }\end{array}$ & \\
\hline Group CBT & & & Individual Psychoanalysis & \\
\hline
\end{tabular}

Note. $\mathrm{CBT}=$ cognitive behavioral therapy. 